\title{
Potent anti-tumor activity of a syringolin analog in multiple myeloma: a dual inhibitor of proteasome activity targeting $\beta 2$ and $\beta 5$ subunits
}

\author{
Takashi Yoshida ${ }^{1}$, Masaki Ri ${ }^{1}$, Takashi Kanamori ${ }^{1}$, Sho Aoki ${ }^{1}$, Reham Ashour ${ }^{1}$, \\ Shiori Kinoshita ${ }^{1}$, Tomoko Narita ${ }^{1}$, Haruhito Totani ${ }^{1}$, Ayako Masaki ${ }^{1}$, Asahi Ito ${ }^{1}$, \\ Shigeru Kusumoto${ }^{1}$, Takashi Ishida ${ }^{1}$, Hirokazu Komatsuㄹ, Shun Kitahata ${ }^{2}$, Takuya \\ Chiba $^{2}$, Satoshi Ichikawa ${ }^{2}$ and Shinsuke Iida ${ }^{1}$ \\ ${ }^{1}$ Department of Hematology and Oncology, Nagoya City University Graduate School of Medical Sciences, Nagoya, Japan \\ ${ }^{2}$ Center for Research and Education on Drug Discovery, Faculty of Pharmaceutical Sciences, Hokkaido University, Hokkaido, Japan \\ Correspondence to: Masaki Ri, email: rrmasaki@ybb.ne.jp
}

Keywords: multiple myeloma; syringolin analog; dual inhibitor; proteasome; bortezomib resistance

Received: July 12, $2017 \quad$ Accepted: December 03, $2017 \quad$ Published: January 11, 2018

Copyright: Yoshida et al. This is an open-access article distributed under the terms of the Creative Commons Attribution License 3.0 (CC BY 3.0), which permits unrestricted use, distribution, and reproduction in any medium, provided the original author and source are credited.

\section{ABSTRACT}

Proteasome inhibitors (PI), mainly targeting the $\beta 5$ subunit of the 205 proteasome, are widely used in the treatment of multiple myeloma (MM). However, PI resistance remains an unresolved problem in the therapy of relapsed and refractory MM. To develop a new PI that targets other proteasome subunits, we examined the anti-MM activity of a novel syringolin analog, syringolog-1, which inhibits the activity of both the $\beta 5$ and $\beta 2$ subunits. Syringolog-1 exhibited marked cytotoxicity against various MM cell lines and anti-tumor activity towards bortezomib (Btz)-resistant MM cells through the dual inhibition of chymotrypsin-like ( $\beta 5$ subunit) and trypsin-like ( $\beta 2$ subunit) activities. MM cells, including Btz-resistant cells, showed elevated CHOP and NOXA expression after syringolog-1 treatment, indicating the induction of excessive endoplasmic reticulum stress during syringolog-1 treatment. Similar activities of syringolog-1 were also observed in freshly prepared MM cells derived from patients. To clarify the anti-tumor mechanism of dual inhibition of both the $\beta 5$ and $\beta 2$ subunits of the proteasome, PSMB5 and PSMB7 were co-inhibited in MM cells. This resulted in increased apoptosis of MM cells accompanied by accumulation of ubiquitinated proteins compared to inhibition of either PSMB7 or PSMB5 alone, indicating an enhanced effect by double inhibition of $\beta 2$ and $\beta 5$ activities. In conclusion, this syringolin analog, a dual inhibitor of proteasome $\beta 2$ and $\beta 5$ activities, exhibited potent anti-tumor effects on MM cells and may be useful for overcoming Btz-resistance in the treatment of MM.

\section{INTRODUCTION}

Multiple myeloma (MM) is a mature B cell neoplasm characterized by abundant secretion of monoclonal immunoglobulin and other unfavorable symptoms represented as myeloma-defining events [1]. Several novel agents have been developed and introduced to treat this incurable disease. Among them, the proteasome inhibitor bortezomib (Btz) was the first proteasome inhibitor approved for clinical use and is widely used in the treatment of MM including newly diagnosed and relapsed/refractory cases [2]. Recently, novel proteasome inhibitors have been introduced and are expected to be effective and less toxic in the treatment of MM [3, 4] .

The $26 \mathrm{~S}$ proteasome is a catalytic complex composed of the 20S proteasome and 19S regulatory subunit and promotes the proteolysis of ubiquitinated proteins to be degraded [5]. The $20 \mathrm{~S}$ proteasome has three functional activities: caspase-like (C-L, $\beta 1$ subunit), trypsin-like (T-L, $\beta 2$ subunit), and chymotrypsin-like (CT-L, $\beta 5$ subunit) activities. The anti-tumor effect of Btz 
and novel proteasome inhibitors in clinical use mainly depend on the inhibition of CT-L activity [5]. In fact, two reversible proteasome inhibitors, Btz and ixazomib, markedly inhibit CT-L activity and weakly inhibit C-L activity [6, 8]. Carfilzomib, an irreversible proteasome inhibitor, specifically targets CT-L activity [7]. Inhibition of CT-L activity is considered a key strategy for treating MM cells. However, several studies have proposed that the mechanism of action of Btz resistance is mainly associated with activity of the $\beta 5$ subunit, such as mutations in PSMB5 ( $\beta 5$ subunit coding gene) $[9,10]$ or upregulated expression of proteasome subunits [11-14]. Specifically, inhibiting the activity of the $\beta 5$ subunit would not provide a sufficient anti-tumor effect in MM cases showing Btz resistance. Therefore, targeting proteins other than the $\beta 5$ subunit is considered a novel strategy for inducing cell death in MM cells that are insensitive to $\beta 5$ inhibition.

Syringolin A is a novel proteasome inhibitor extracted from Pseudomonas syringae pv Syringae, and belongs to the syrbactin class of proteasome inhibitors [15]. Although this compound irreversibly inhibits $20 \mathrm{~S}$ proteasome activity, it has poor cell membrane permeability because of its hydrophilicity, necessitating the administration of high doses at the micromolar level to effectively inhibit proteasome activity [16]. Therefore, we developed a new syringolin analog showing strong and stable proteasome inhibition and improved the biological activity of this compound. We recently developed several novel syringolin analogs exhibiting remarkable proteasome inhibition with favorable cell permeability $[17,18]$ and potent proteasome inhibition at the nanomolar level in human tumor cells.

Here, we examined the anti-MM effect of a novel syringolin compound named as syringolog-1 (Figure 1), which inhibits both CT-L and T-L activities in MM cells, and found that dual inhibition of the CT-L and T-L activities of the $20 \mathrm{~S}$ proteasome was a potent treatment strategy for MM, including Btz-resistant cases.

\section{RESULTS}

\section{Syringolog-1 exhibits an anti-tumor effect on bortezomib-resistant MM cells through dual inhibition of chymotrypsin-like and trypsin-like activities}

A total of 10 cell lines, including $4 \mathrm{MM}$ cells, 3 lymphoma cells, and 3 cells harboring Btz resistance, were utilized to evaluate the growth inhibitory effect of syringolog-1. The mean $\mathrm{IC}_{50}$ values of syringolog-1 on these cells were approximately $10 \mathrm{nM}$, with most values lower than the $\mathrm{IC}_{50}$ value of Btz (Table 1). Both MM cells and lymphoma cells showed a remarkable decrease in cell viability upon treatment with around $10 \mathrm{nM}$ syringolog-1.

Three Btz-resistant cell lines, KMS-11/Btz, OPM2/Btz, and MT-4/Btz, showed a 3.1- $\left(\mathrm{IC}_{50}=17.4 \mathrm{nM}\right)$, $3.9-\left(\mathrm{IC}_{50}=5.1 \mathrm{nM}\right)$, and $5.3\left(\mathrm{IC}_{50}=6.4 \mathrm{nM}\right)$-fold higher resistance to syringolog-1 compared to their parental cells, KMS-11 ( $\left.\mathrm{IC}_{50}=5.7 \mathrm{nM}\right)$, OPM-2 $\left(\mathrm{IC}_{50}=1.3 \mathrm{nM}\right)$, and MT-4 $\left(\mathrm{IC}_{50}=1.2 \mathrm{nM}\right)$. This resistance to syringolog-1 was significantly lower than the resistance to Btz, which was 44.4-fold in KMS11/Btz, 104.6-fold in OPM2/Btz, and 8.4-fold in MT-4/Btz (Table 1).

Upon measuring apoptosis induced by syringolog-1 treatment, two MM cell lines, KMS-11 and OPM-2, showed significant levels of apoptosis in a dose-dependent manner (Figure 2A, left). A similar result was observed in the corresponding Btz-resistant cell lines (Figure 2A, right).

To evaluate syringolog-1-induced proteasome inhibition, alterations in $20 \mathrm{~S}$ proteasome activities were measured upon syringolog-1 treatment in various cell lines, including Btz-resistant cells. Similar to Btz treatment, most cells, including MM and lymphoma cells, showed a remarkable reduction in CT-L activity by at least $80 \%$ and mild or no reduction in C-L activity (Figure 2B-2C: left, right). Unlike with Btz, a moderate to mild reduction in T-L activity of approximately $20-50 \%$ was observed in most cells tested; this reduction was also observed in Btz-resistant cells (Figure 2B-2C: middle), suggesting that inhibition of T-L activity was not affected by Btz resistance during syringolog-1 treatment.

Next, we evaluated the inhibitory effect of various concentrations of syringolog-1 on the above three activities. As shown in Figure 3A, 4 MM cell lines, KMS11, OPM-2, U266, and RPMI8226, showed a remarkable reduction in CT-L activity, moderate to mild reduction in $\mathrm{T}-\mathrm{L}$ activity, and mild reduction in $\mathrm{C}$-L activity in a dosedependent manner. Similar reductions in the activity of each proteasome were observed in the two Btz-resistant cell lines (Figure 3B).

\section{Alteration of ubiquitin-proteasome, endoplasmic reticulum stress, and apoptosis-related pathways during syringolog- 1 treatment}

To clarify the mechanism of action underlying syringolog-1-induced cell death, alterations in pathways associated with the unfolded protein response (UPR) and endoplasmic reticulum (ER) stress were assessed. After syringolog-1 treatment, two MM cell lines showed increased expression of CHOP, ATF3, and XBP1 and accumulation of poly-ubiquitin proteins related to UPR and ER stress, as well as upregulation of NOXA and activation of cleaved caspase 3 (Figure 4A). Similar results were observed in two Btz-resistant cell lines tested in the same manner (Figure 4D). Phosphorylation of c-Jun and ERK1/2, and activation of p27 and Hsp70, considered as indicators of the cell stress response, were observed upon syringolog-1 treatment (Figure 4B). These results were also observed following Btz treatment. Two Btz-resistant cell lines were similarly tested with parental cells. As shown in Figure 4C, Btz resistant cells showed minimal 
changes in phosphorylation and activation of the above substrate after bortezomib treatment. However, following treatment with syringolog-1, these cells showed the same phosphorylation and activation levels as treatment with each substrate in parental cells.

To examine the effect of syringolog- 1 on the cell cycle distribution, the cell cycle was analyzed before and after syringolog-1 treatment. As shown in Figure 4E and $4 \mathrm{~F}$, accumulation of the $\mathrm{G} 2 / \mathrm{M}$ phase was observed in both $\mathrm{MM}$ cells after syringolog-1 treatment.

\section{Evaluation of syringolog-1-induced anti-tumor effects in primary MM cells}

Eight primary MM samples derived from patients were utilized to examine syringolog-1-induced antitumor effects using the same methods used for the cell lines described above. The median $\mathrm{IC}_{50}$ values of syringolog-1 and Btz on 8 primary MM cells were 8 and $13 \mathrm{nM}$, respectively. Among the 5 primary MM cells showing clinical sensitivity to Btz-based therapy, most cases showed $\mathrm{IC}_{50}$ values of $15 \mathrm{nM}$ of lower following Btz treatment (Figure 5A). These cells showed equal or slightly higher $\mathrm{IC}_{50}$ values after syringolog-1 treatment. In the 3 cases with clinical refractory to Btz-based therapy, two cases showed lower $\mathrm{IC}_{50}$ values of 8.5 and $8.8 \mathrm{nM}$ after syringolog-1 treatment compared to Btz with values of 14.4 and $16.1 \mathrm{nM}$ (Figure 5B). One sample showed nearly equal $\mathrm{IC}_{50}$ values of $2.9 \mathrm{nM}$ after syringolog-1 treatment and $2.8 \mathrm{nM}$ after Btz treatment. Regarding inhibition of $20 \mathrm{~S}$ proteasome activities, Btz inhibited CT-L activity, whereas syringolog-1 showed not only remarkable inhibition of CT-L but also moderate inhibition of T-L activity (Figure 5C). To evaluate the cytotoxic effect of syringolog-1, peripheral blood mononuclear cells (PBMCs) from healthy individuals were incubated with various concentrations of syringolog-1. As shown in Figure 5D, no or a low cytotoxic effect was observed in PBMCs at concentrations below $100 \mathrm{nM}$.

In immunoblot analysis, three primary MM cell

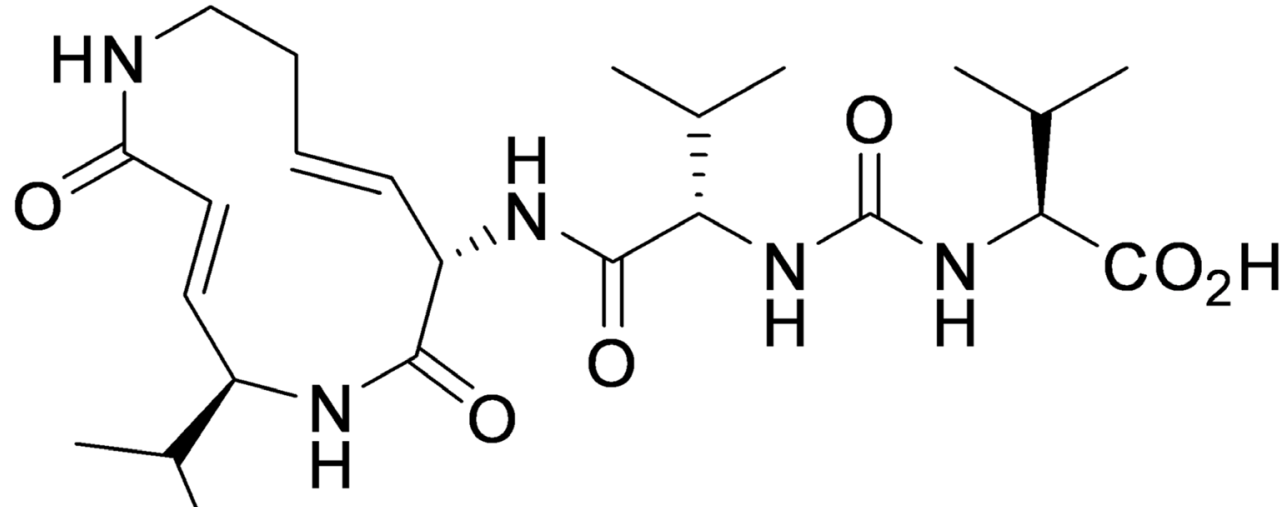

\section{syringolin A}

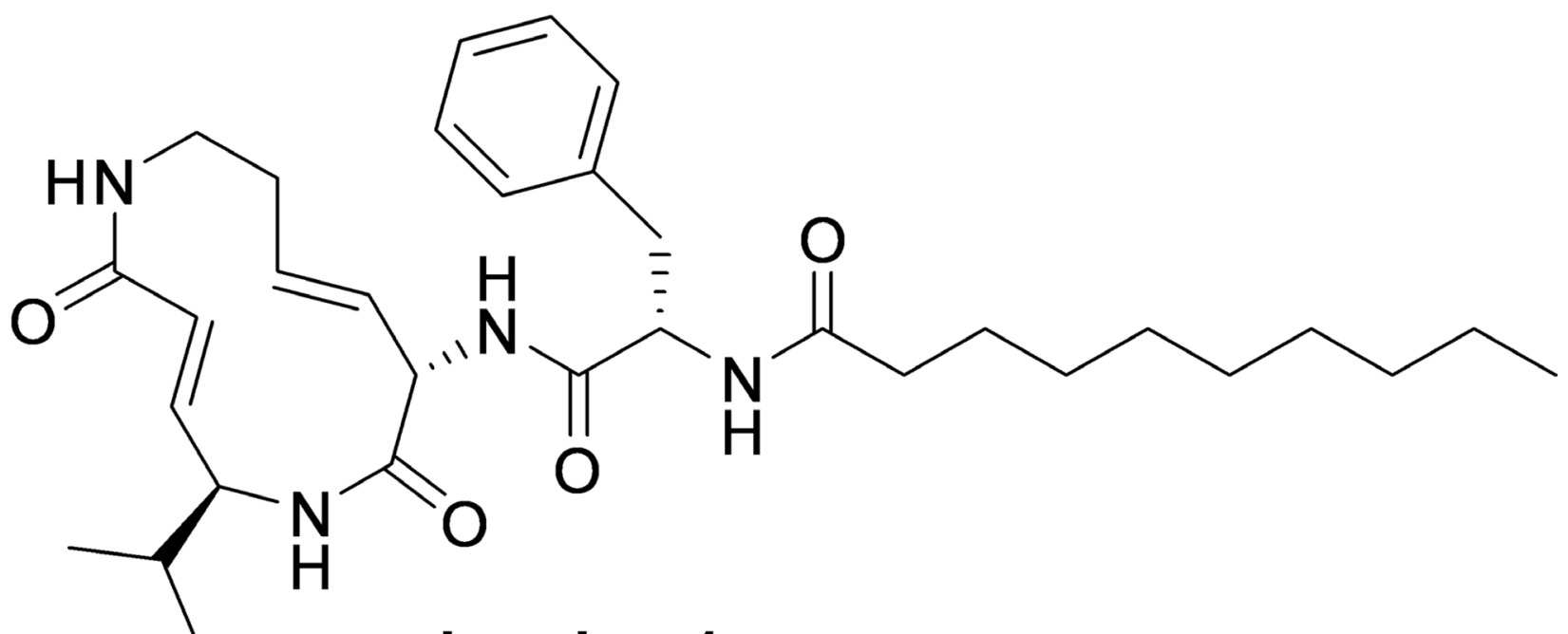

syringolog-1

Figure 1: Structure of syringolin A and its synthetic analog, syringolog-1. The structural formula of syringolog-1 is indicated. 
A
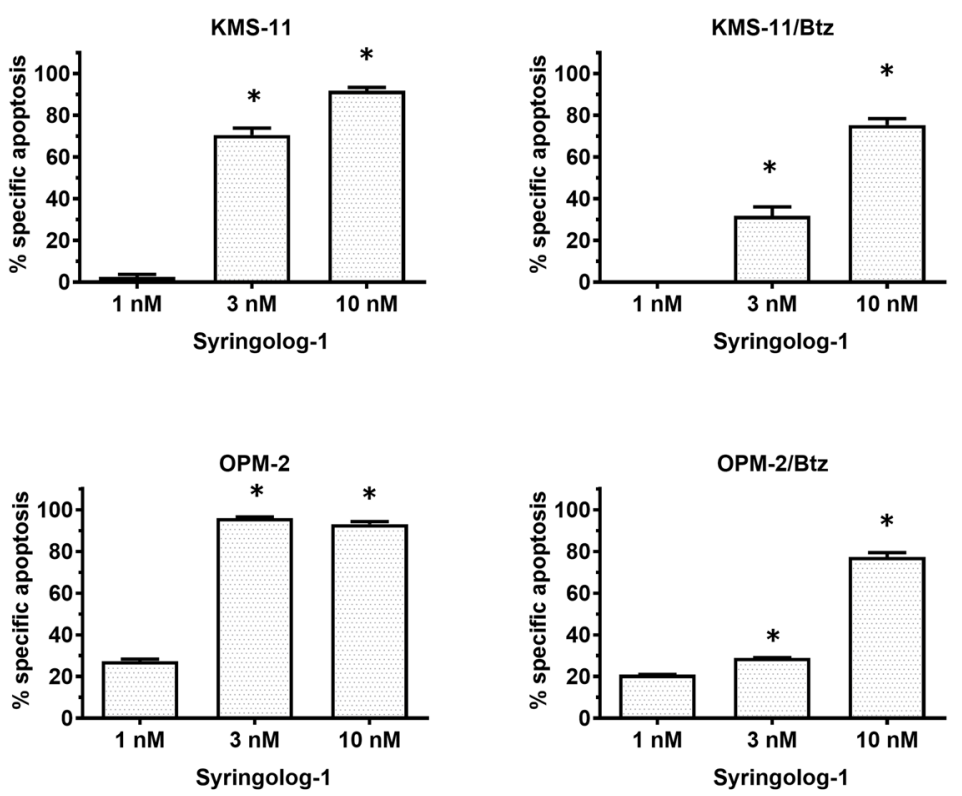

B

$\beta 1$ (caspase-like) activity

$\beta 2$ (trypsin-like) activity

$\beta 5$ (chymotrypsin-like) activity
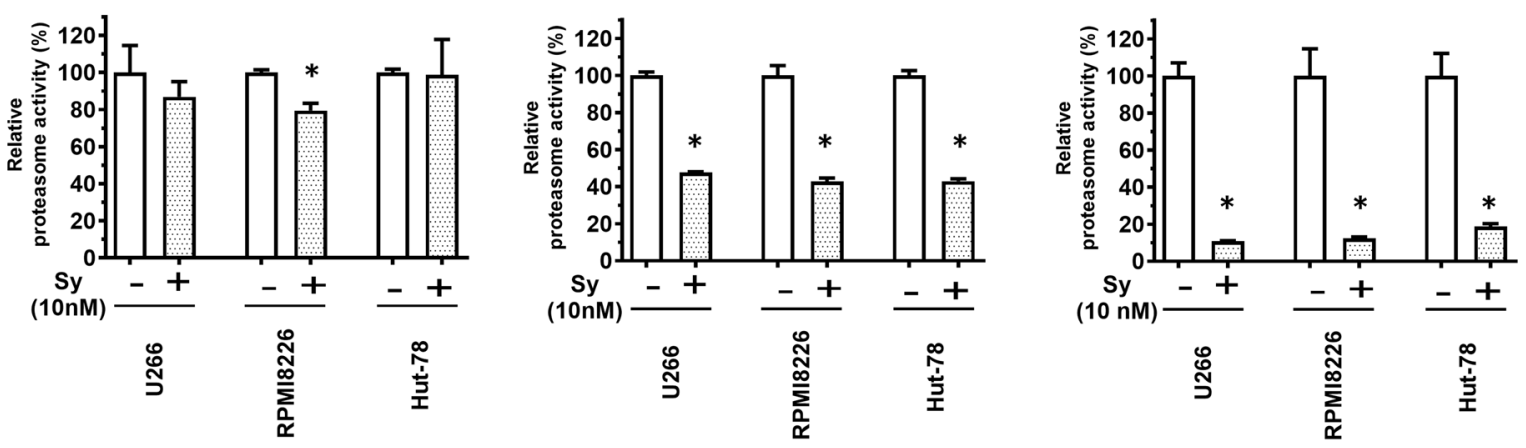

C

$\beta 1$ (caspase-like) activity

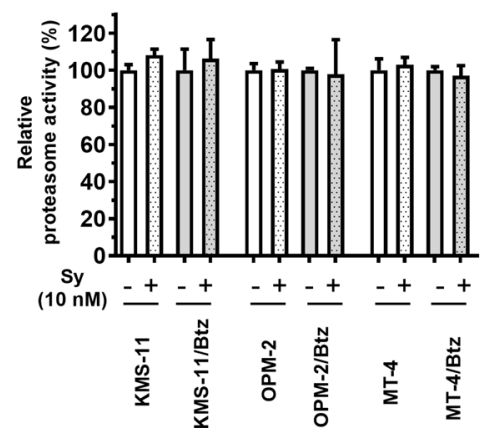

$\beta 2$ (trypsin-like) activity

$\beta 5$ (chymotrypsin-like) activity
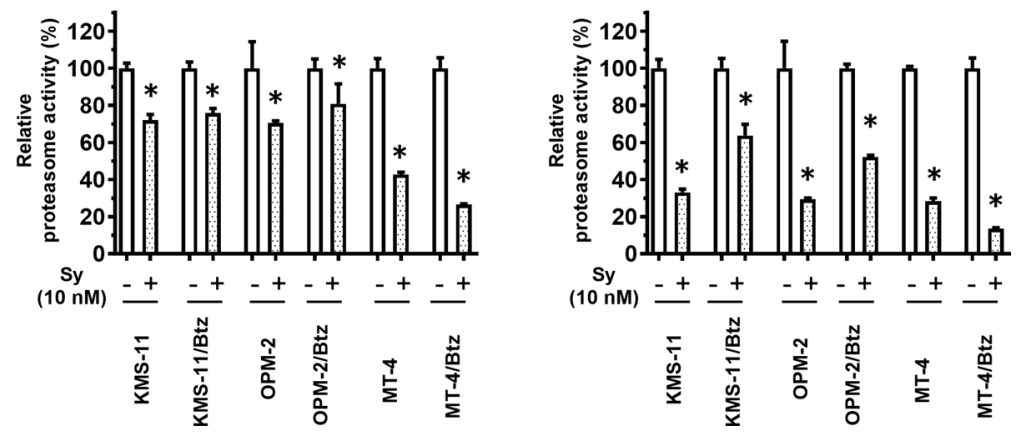

Figure 2: Induction of apoptosis and alteration of proteasome activities in multiple myeloma cells treated with syringolog-1. (A) Percent specific apoptosis in multiple myeloma (MM) cell lines and bortezomib (Btz)-resistant cell lines was detected after incubation with $10 \mathrm{nM}$ of syringolog-1 for $16 \mathrm{~h}$. ${ }^{*}$ represents statistically significant $(p<0.05)$ by Dunnett's post-test. (B) MM cell lines were subjected to the analysis of proteasome activities after incubation with $10 \mathrm{nM}$ syringolog-1 (Sy) for $6 \mathrm{~h}$. (C) Btz-resistant MM cell lines and their parental cells were similarly analyzed of proteasome activities. " represents statistically significant by Student's $t$-test $(p<0.05)$. 
lines accumulated poly-ubiquitin proteins and cleaved caspase-3 upon syringolog-1 treatment (Figure 5E).

\section{Effect of dual inhibition of PSMB5 and PSMB7 on tumor cells}

Unlike Btz, syringolog-1 is thought to target both CT-L and T-L activities, which may contribute to its enhanced anti-tumor activity in MM cells. To elucidate the significance of dually suppressing CT-L and T-L $20 \mathrm{~S}$ proteasome activities, the expression of PSMB5 and PSMB7, encoding the $\beta 5$ and $\beta 2$ subunits, respectively, was suppressed in tumor cells and then cell viability was evaluated. In U266 cells, when gene expression of either PSMB5 or PSMB7 was silenced by siRNA (Figure 6A), $P S M B 7-k n o c k d o w n$ cells showed a higher rate

\section{A}
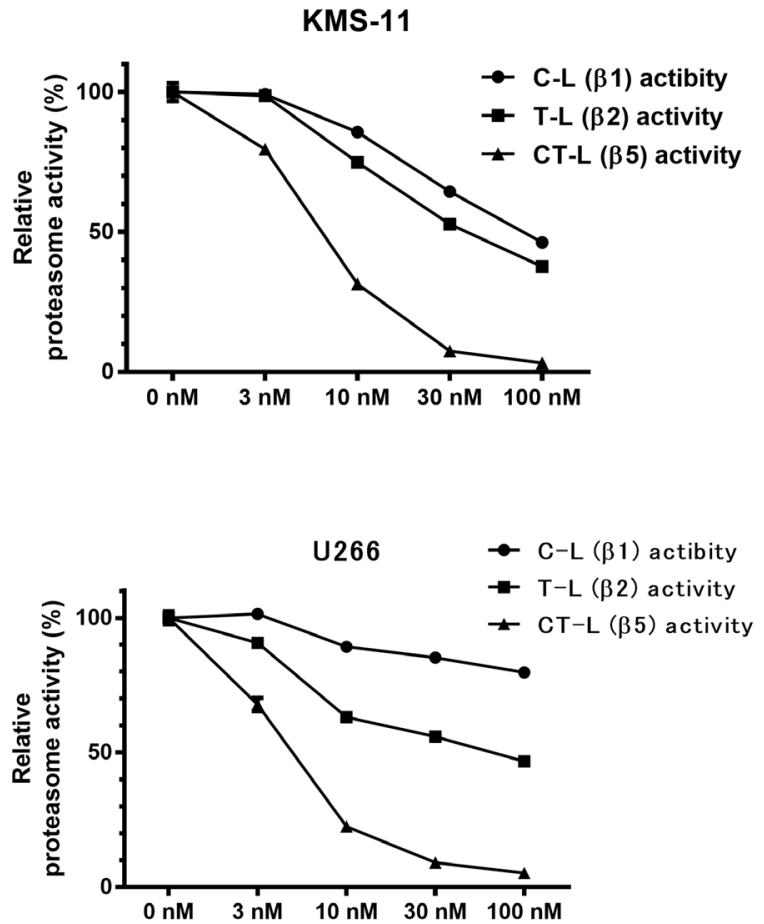

B

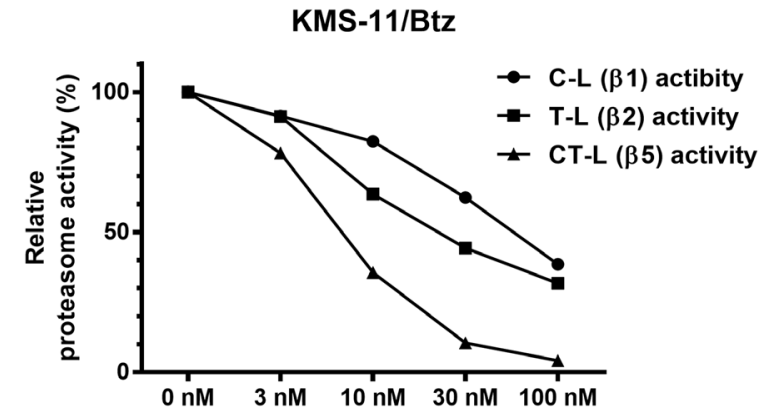

of apoptosis estimated as $25.4 \%$ compared to PSMB5 -knockdown and control cells, which exhibited rates of $10.3 \%$ and $13.8 \%$ apoptosis, respectively. Similarly, greater apoptosis in PSMB7-knockdown cells was observed in two other cell lines, KMS-11 and Hut78 (Figure 6B-6C). In the analysis of gene expression in whole proteasomes including PSMB5 ( $\beta 5$ ), PSMB8 (i 135 ), PSMB7 ( $\beta 2$ ), PSMB10 (i $\beta 2$ ), PSMB6 ( $\beta 1$ ), and PSMB9 (i 1 1), these genes alternated or showed only slight in their expression following silencing of PSMB5 or PSMB7 in three tumor cells (Figure 6D).

Next, dual inhibition of PSMB5 and PSMB7 were performed in tumor cells using a combination of each specific siRNA at a suboptimal dose. As shown in Figure 6E, single inhibition of either PSMB5 or PSMB 7 at suboptimal concentrations showed decreased the
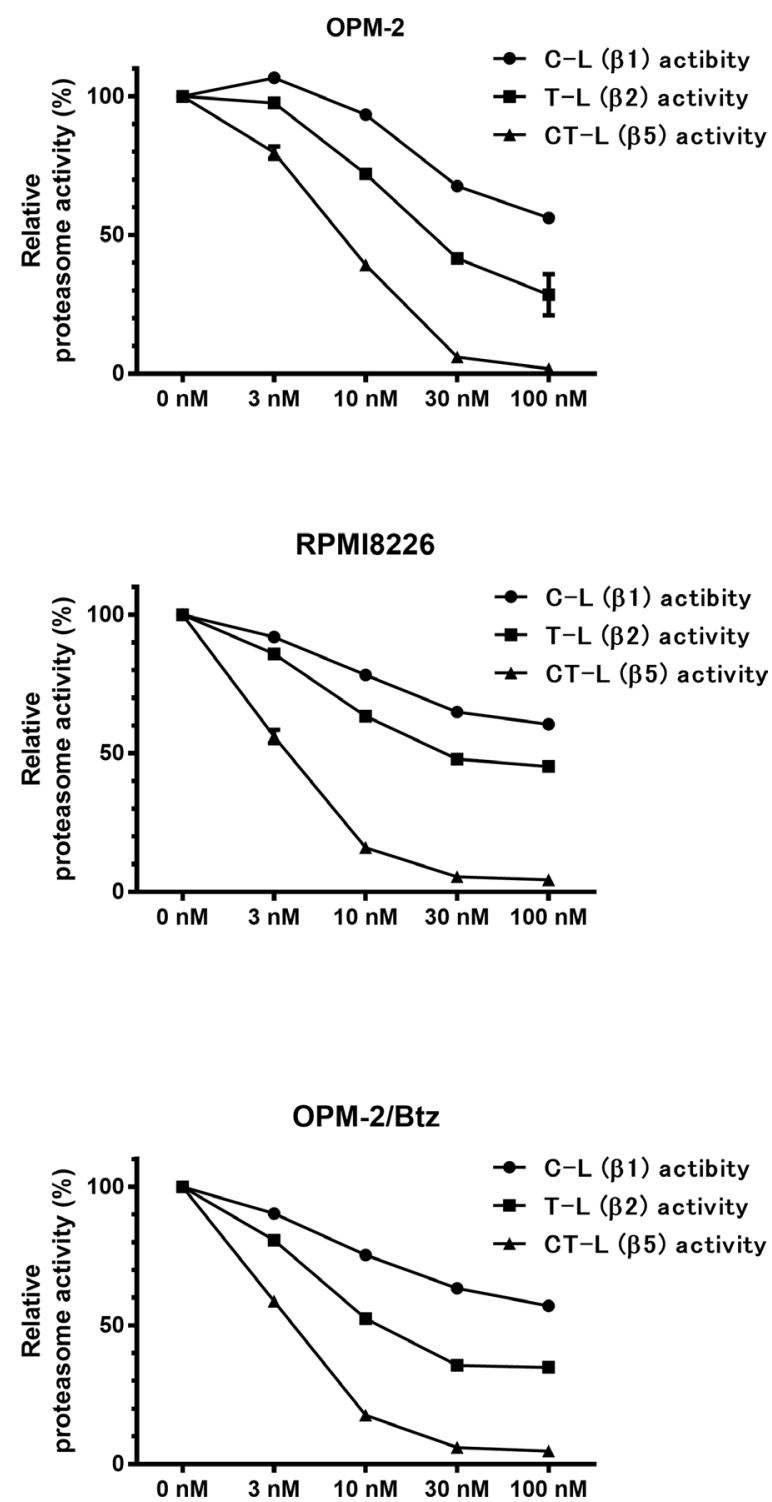

Figure 3: Alteration of proteasome activities in multiple myeloma cells treated with various concentration of syringolog-1. (A) Six MM cells were subjected to the analysis of proteasome activities after incubation with indicated dose of syringolog-1 for $6 \mathrm{~h}$. Each value was calculated as the mean value of triplicate experiments. (B) Two Btz-resistant cell lines were analyzed similarly. 
A

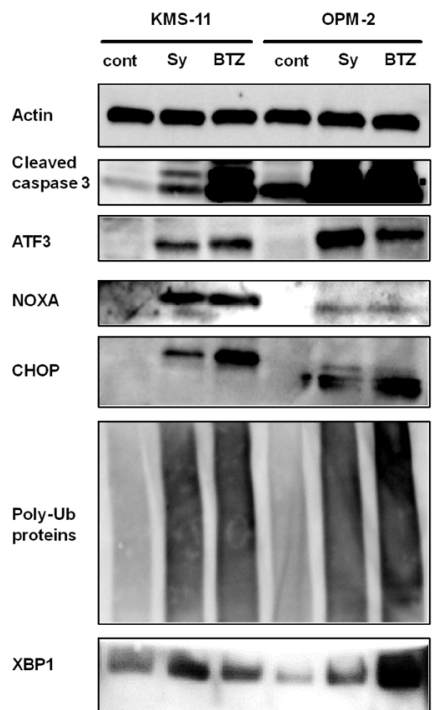

B

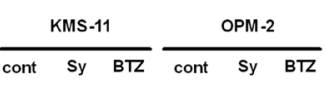

Actin

p-c-JUN

c-JUN

p27

HSP70

(1)

PERK $1 / 2$

ERK1/2
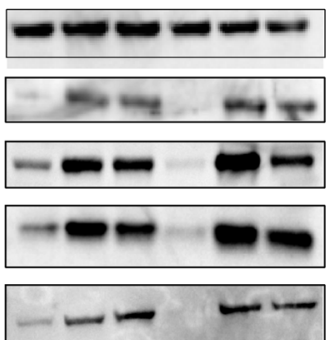

$\square+2$

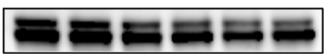

C

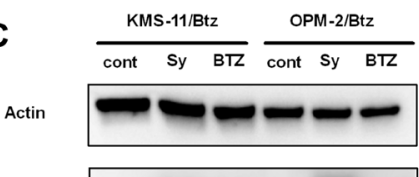

p-c-JUN

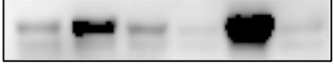

c-JUN

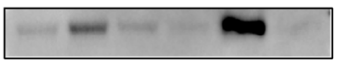

p27

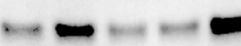

HSP70

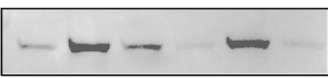

PERK1/2

$=-$

ERK1/2

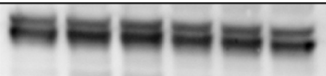

D

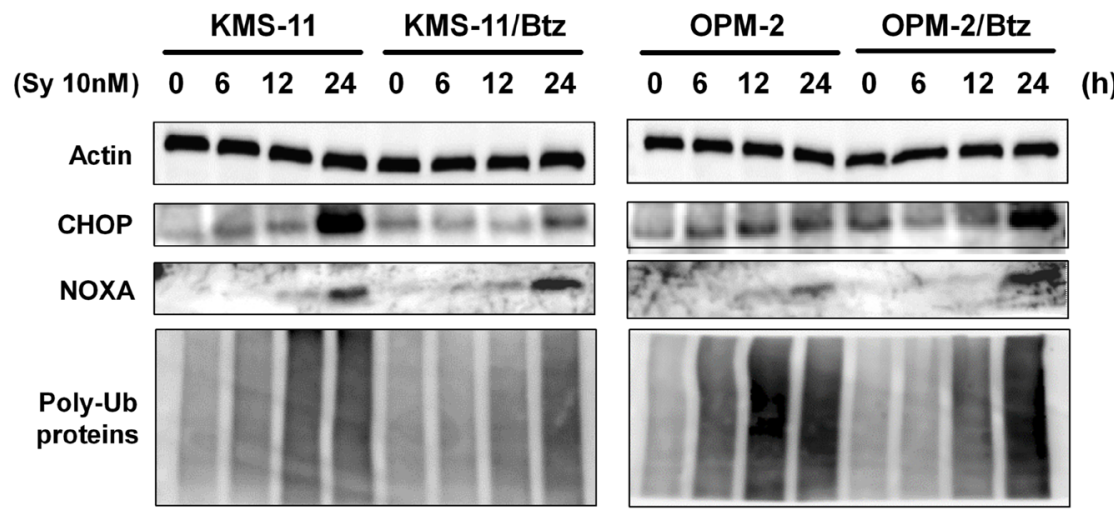

E

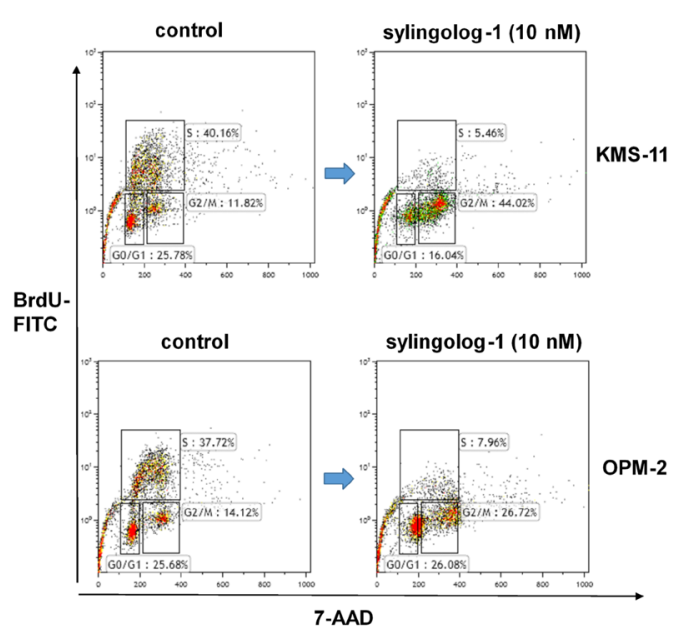

F
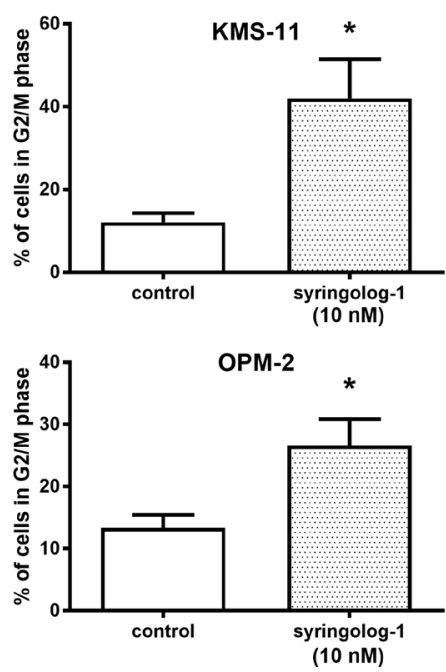

Figure 4: Evaluation of ubiquitin-proteasome, ER stress, and apoptosis-related pathways after syringolog-1 treatment by immunoblot analysis. (A-C) Two multiple myeloma (MM) cells, KMS-11 and OPM-2, and Btz-resistant cells, KMS-11/Btz and OPN-2/Btz, were incubated with $10 \mathrm{nM}$ of syringolog-1 (Sy) or bortezomib (Btz) for $16 \mathrm{~h}$, and subjected to the analysis of changes in ubiquitin-proteasome, ER stress, and apoptosis-related pathways. (D) Btz-resistant MM cell lines and their parental lines were similarly evaluated. (E) Analysis of cell cycle distribution before and after the $10 \mathrm{nM}$ of syringolog-1 treatment for $16 \mathrm{~h}$. A representative case of three independent experiments. (F) Comparison of the ratio in G2/M phase between the control and the treatment by $10 \mathrm{nM}$ of syringolog-1 for $16 \mathrm{~h}$ in two MM cells. ${ }^{*}$ represents statistically significant by Student's $t$-test $(p<0.05)$. 
A

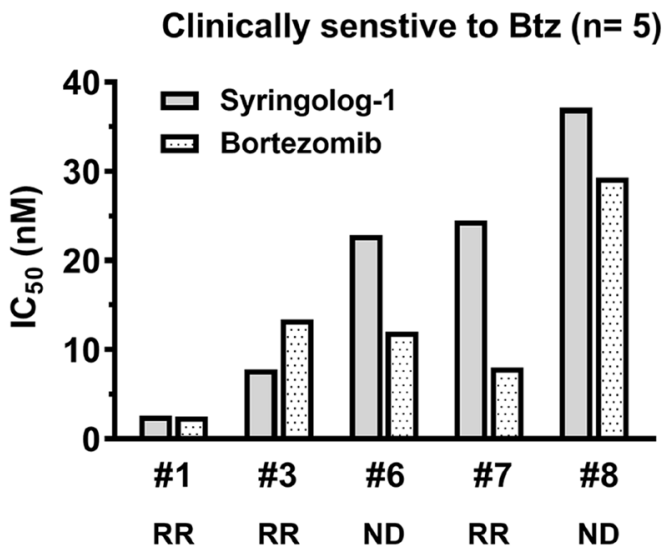

C

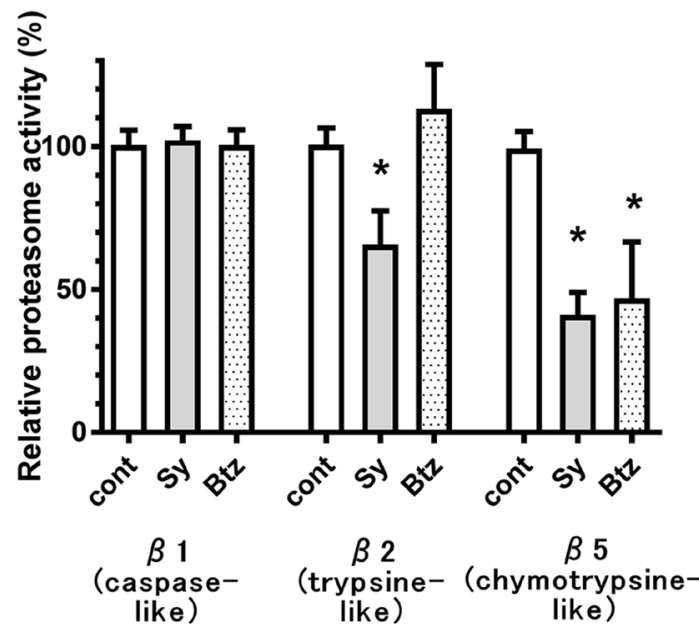

B

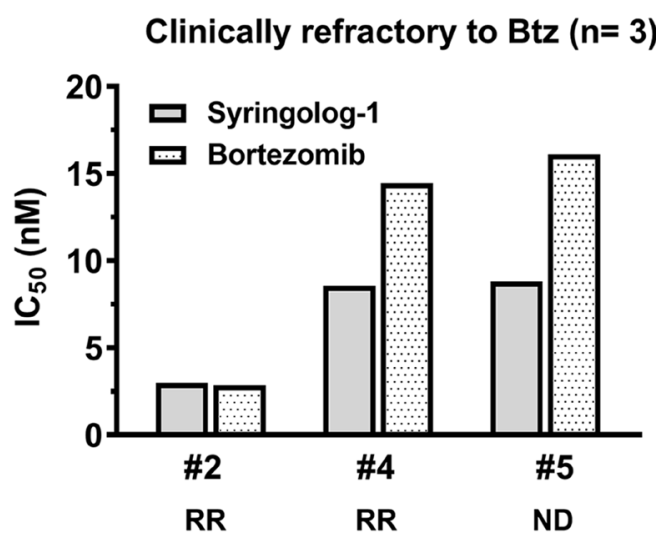

D

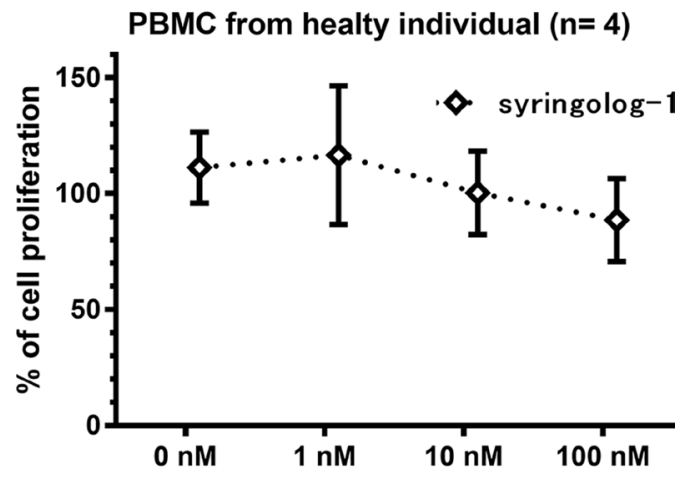

$\mathbf{E}$

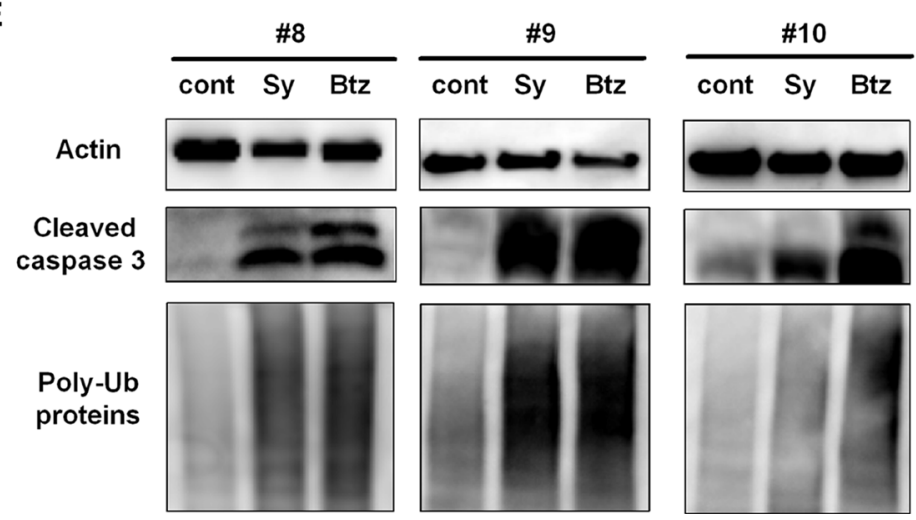

Figure 5: Evaluation of syringolog-1 activity in primary MM cells from patients. (A-B) Cytotoxicity of syringolog-1 (Sy) or bortezomib (Btz) was tested on 8 primary MM cells. $\mathrm{IC}_{50}$ values of Sy on each primary MM cell were calculated from the triplicate experiments. A. 5 cases clinically sensitive to Btz-based therapy. (B) 3 cases clinically refractory to Btz-based therapy. RR: relapsed and or refractory, ND: newly diagnosed. (C) 20S proteasome activities in 8 primary MM cells were evaluated after incubation with or without 10 $\mathrm{nM}$ of Sy or Btz for $6 \mathrm{~h}$. (D) Four peripheral blood mononuclear cells from healthy individuals were analyzed for cytotoxic effect induced by Sy treatment at the indicated dose for $48 \mathrm{~h}$. (E) Accumulation of poly-ubiquitinated proteins and expression of cleaved caspase-3 were evaluated in 3 primary MM cell lines after incubation with $10 \mathrm{nM}$ of syringolog-1 or Btz for $16 \mathrm{~h} .{ }^{*}$ represents statistically significant $(p<$ 0.05 ) by Dunnett's post-test. 
A

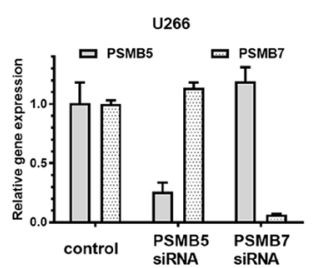

C
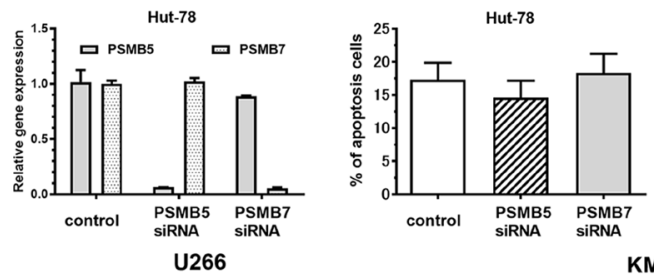

D

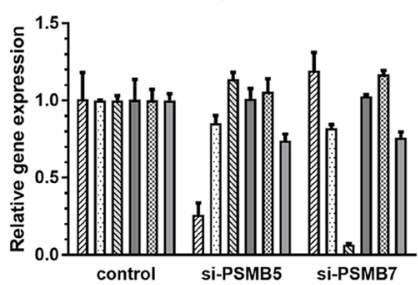

E

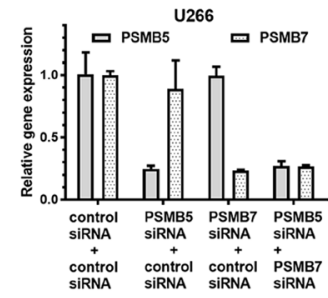

G

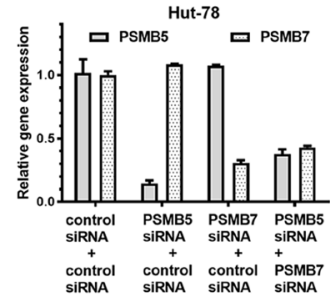

H
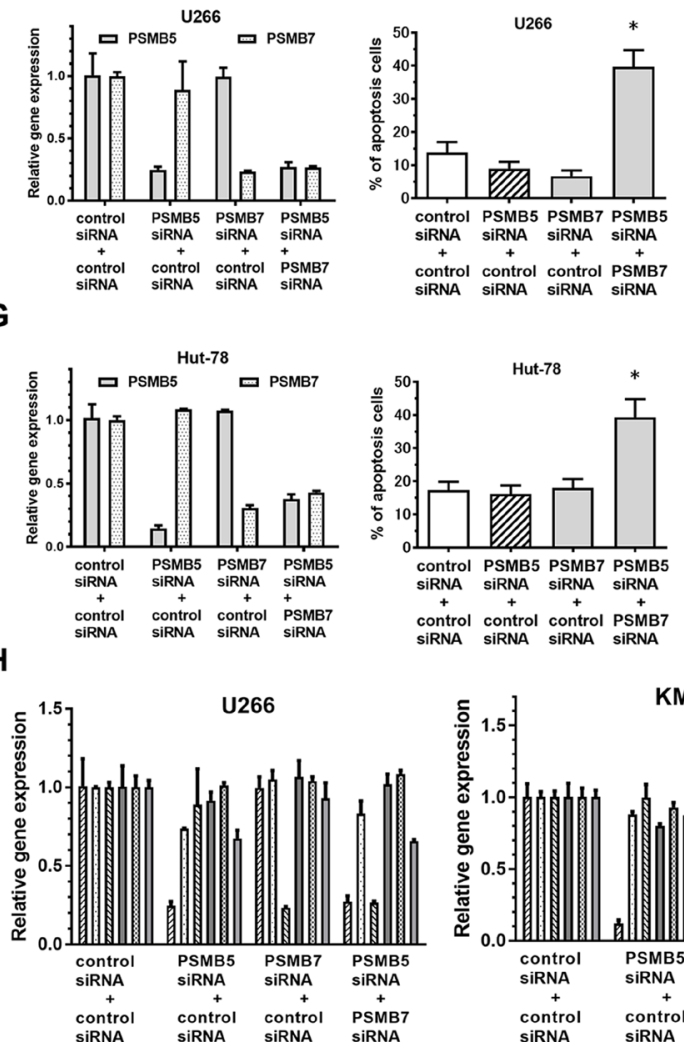

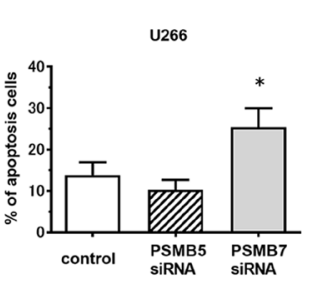

B
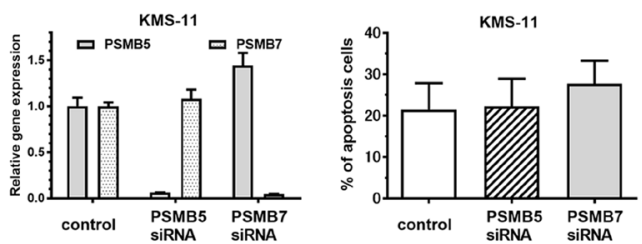
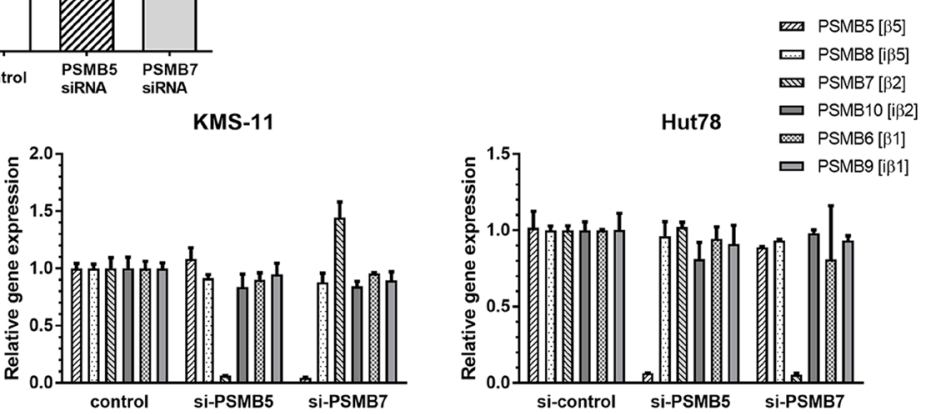

$\mathbf{F}$
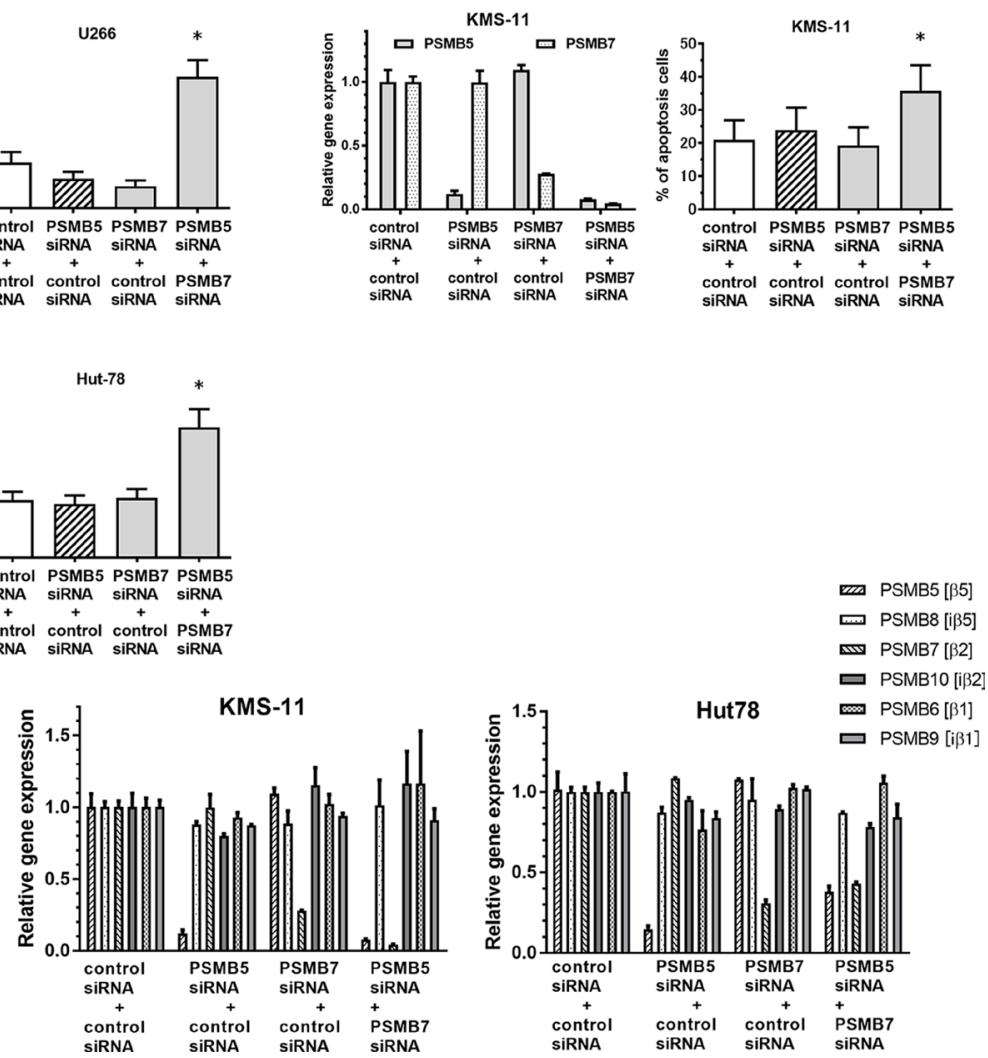

Figure 6: Apoptosis induction and altered expression of ubiquitinated proteins by co-inhibition of expression of PSMB5 and PSMB7 in tumor cells. (A-C) Two MM cell lines, U266 and KMS-11, and a lymphoma cell line, Hut78, were subjected to the inhibition of either $P S M B 5$ or $P S M B 7$ by transfection with specific siRNA, and apoptosis induction was subsequently analyzed. (D) Alteration of six genes, coding proteasomes, were evaluated at the expression level after transfection of siRNA targeting PSMB5 or PSMB7 in tumor cell lines. (E-G) Three cell lines were subjected to co-inhibition of PSMB5 and PSMB7 using suboptimal doses of each specific siRNA. (H) Alteration of six genes, coding proteasomes, were evaluated at the expression level after transfection of siRNA targeting $P S M B 5$ and or PSMB 7 in tumor cell lines. " represents statistically significant $(p<0.05)$ by Dunnett's post-test. 
progression of apoptosis by $9.0 \%$ and $6.7 \%$, respectively. However, the combination of these suboptimal knockdown conditions enhanced apoptosis by approximately $39.6 \%$ compared to each single inhibition (Figure 6E). A similar enhancement of apoptosis was also confirmed in the cell lines KMS-11 and Hut78, which were tested in the same manner (Figure 6F-6G). In the analysis of gene expression in whole proteasomes, the expression of the 6 genes coding each proteasome was not altered or was only slightly changed after combined transfection with a suboptimal dose of the two siRNAs targeting PSMB5 and PSMB7 (Figure 6H) in three tumor cell lines.

In immunoblot analysis, knockdown of either PSMB5 or PSMB7 fully suppressed the $\beta 5$ and $\beta 2$ subunits in U266 cells (Figure 7A, left). Regarding the accumulation of poly-ubiquitinated proteins, $P S M B 7$ silencing induced greater accumulation of poly ubiquitinated proteins than PSMB5 silencing (Figure 7A, left). When evaluating the dual inhibition of PSMB5 and $P S M B 7$, combining suboptimal inhibition conditions of the $\beta 5$ and $\beta 2$ subunits triggered more potent accumulation of poly-ubiquitinated proteins and over-expression of XBP1 than suboptimal suppression of either the $\beta 5$ or $\beta 2$ subunit alone, indicating excess ER stress (Figure7A, left). The same results of excessive ER stress were observed in KMS-11 cells with dual inhibition of PSMB5 and PSMB7 (Figure 7A, right). Similarly, facilitated accumulation of poly-ubiquitinated proteins was confirmed in Hut78 cells upon inhibiting both the $\beta 5$ and $\beta 2$ subunits (Figure 7B).

Taken together, these results demonstrate that dually inhibiting the $\beta 2$ and $\beta 5$ subunits of the 20S proteasome had an additive effect on cytotoxicity compared to inhibiting either of these subunits alone.

\section{In vivo anti-tumor activity of syringolog-1 alone in a human MM xenograft model}

To evaluate the in vivo efficacy of syringolog-1 in MM cells, SCID mice subcutaneously inoculated with RPMI-8226 were administered syringolog-1 intraperitoneally twice weekly at either 3 or $5 \mathrm{mg} / \mathrm{kg}$. Syringolog-1 treatment showed robust anti-tumor activity, resulting in significantly smaller tumor volumes compared to control tumors on day 8,11 , and 15 . This activity was similar to the effect of BTZ administration (Figure 8A). No obvious difference in the tumor inhibitory effect was observed upon 3 or $5 \mathrm{mg} / \mathrm{kg}$ injection of syringolog- 1 .

In the analysis of serumfree light chain expressed in inoculated MM cells, the mean value of the lambda light chain in the group with $3 \mathrm{mg} / \mathrm{kg}$ of treatment was generally lower than the levels in the control group, and mean value of the lambda light chain in the group treated with $5 \mathrm{mg} /$ $\mathrm{kg}$ of syringolog-1 was significantly lower than that in the group with Btz treatment and controls (Figure 8B).

Changes in body weight occurred in the control group, perhaps due to the tumor burden (Figure 8C). No mice showed visible changes in appearance that would indicate toxicity.

Finally, to evaluate the anti-MM activity of syringolog-1 against Btz-resistant MM cells, NOD SCID mice subcutaneously inoculated with Btz-resistant MM cells, OPM-2/Btz were administered with syringolog-1 intraperitoneally, twice weekly, at $5 \mathrm{mg} / \mathrm{kg}$. Syringolog-1 treatment showed significant anti-tumor activity, resulting in smaller tumor volumes compared to control tumors or BTZ administration on day 15 (Figure 8D).

\section{DISCUSSION}

In this study, we developed a new syringolin compound, syringolog-1, and showed its ability to dually inhibit both CT-L and T-L activities. We revealed several features of this compound: (1) marked cytotoxicity of syringolog-1 treatment in Btz-resistant cells through dual inhibition of CT-L and T-L activities, (2) accumulated poly-ubiquitinated proteins and subsequent ER stress in Btz-resistant cells upon syringolog-1 treatment, (3) triggering of progressed apoptosis by co-inhibition of the $\beta 5$ and $\beta 2$ subunits compared to that by inhibition of individual subunits, and (4) anti-myeloma effect of syringolog-1 treatment without any marked side effects in a murine MM model.

In our study, among the 8 primary MM cases tested, 3 cases showed lower sensitivity to syringolog-1 treatment than Btz, represented by slightly higher $\mathrm{IC}_{50}$ values. Although the reason for this low sensitivity in syringolog-1 was unclear, these 3 cases were derived from clinically Btz-sensitive cases, and therefore may have good sensitivity in inhibiting proteasomes $\beta 5$ and $\beta 1$ by Btz treatment than inhibition of $\beta 5$ and $\beta 2$ by syringolog- 1 treatment. Further analysis of a larger number of cases including both Btz-sensitive and refractory cases are needed to evaluate the difference in sensitivity between the two proteasome inhibitors.

As seen in several preclinical studies $[19,20]$, the therapeutic potential of proteasome inhibitors is considered to depend not on the predominant inhibition of a single proteasome activity, such as CT-L activity, but on the multiple inhibition of proteasome activities, such as coinhibition of CT-L and C-L observed in Btz. Carfilzomib (Cfz), a specific and irreversible inhibitor of CT-L activity, was expected to be capable of treating Btz-resistant MM cases; however, it showed decreased clinical efficacy in Btz-resistant cases in the FOCUS study, which targeted Btz- and lenalidomide-resistant MM cases [21, 22] . Cfz mainly improves clinical treatment in patients with $\mathrm{MM}$ who received insufficient Btz administration because of the intolerable side effects of the agent, such as severe peripheral neuropathy and gastrointestinal disorders. In addition, Cfz was shown to have a clinical benefit in the treatment of relapsed and refractory (RR) MM cases when combined with lenalidomide plus dexamethasone treatment [4]. 
Cfz now has potent anti-tumor effects on RR MM cases when this agent is administered at an elevated dose of $20 / 56 \mathrm{mg} / \mathrm{m}^{2}$ [23]. In this administration setting, Cfz has been shown to lose its selectivity of proteasome inhibition and co-inhibit CT-L and T-L activity [24]. In the current study, selective suppression of the $\beta 5$ subunit induced low apoptosis levels in all 3 cell lines tested, including

A

\begin{tabular}{lcccccc}
\hline \multicolumn{5}{c}{ U266 } \\
si-neg & +++ & & & + & ++ & \\
si-PSMB5 & & +++ & & ++ & & ++ \\
si-PSMB7 & & & +++ & & + & +
\end{tabular}
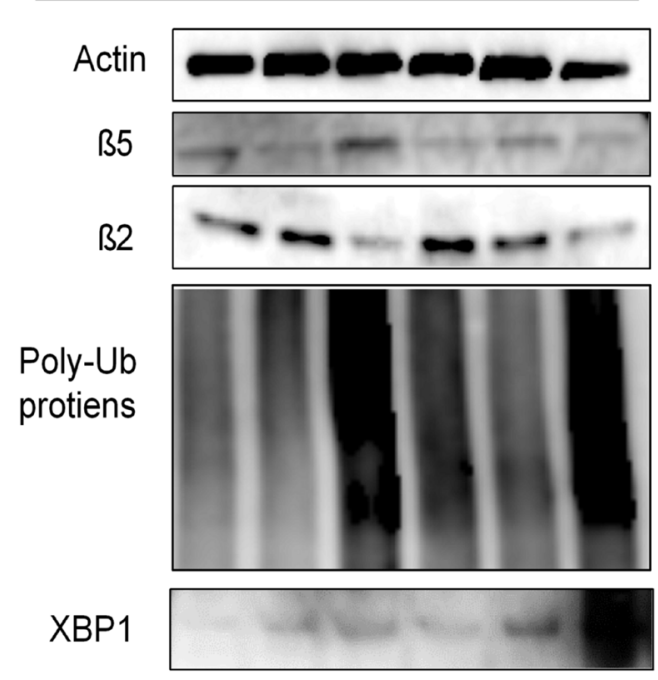

B
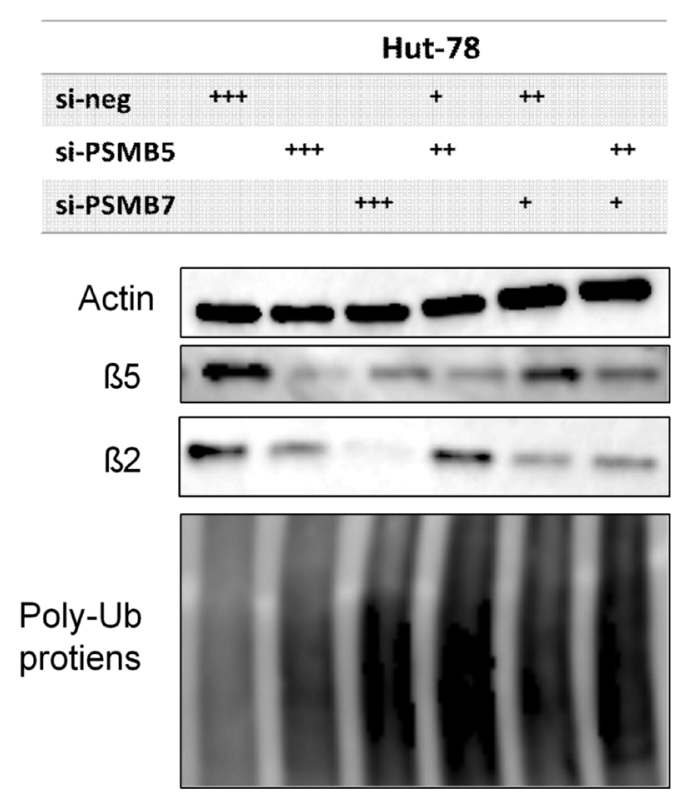

MM and lymphoma cells, compared to the higher levels of apoptosis observed upon dual inhibition of the $\beta 5$ and $\beta 2$ subunits. This result suggests the limited anti-tumor activity of inhibiting a single proteasome activity and the critical role of targeting multiple proteasome activities during MM treatment. To develop an effective method for inhibiting the proteasome to treat MM, the choice of

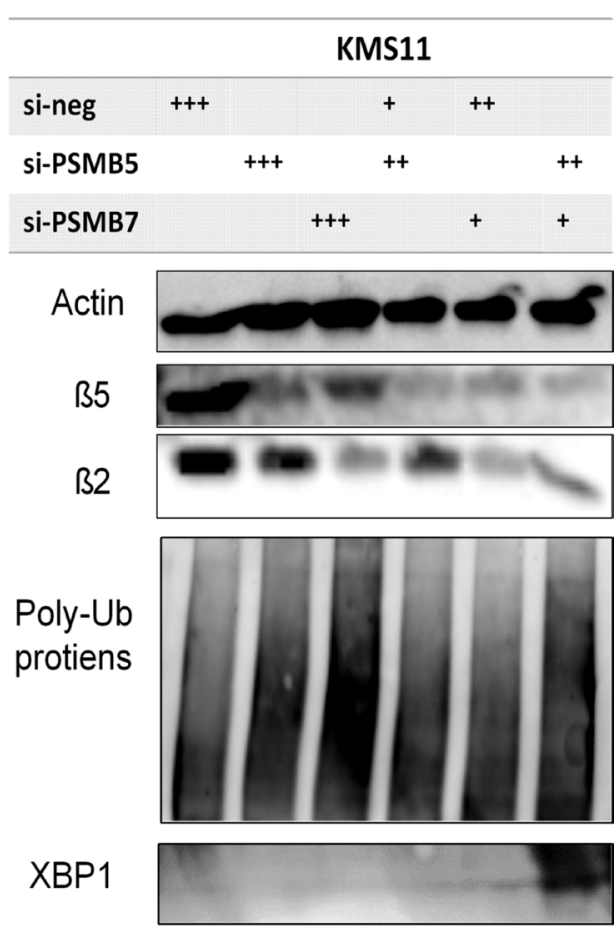

Figure 7: Altered expression of ubiquitinated proteins by co-inhibition of expression of PSMB5 and PSMB7 in tumor cells. (A-B) Altered expression of $\beta 5, \beta 2$, and poly-ubiquitinated proteins was evaluated after single inhibition of PSMB5 or PSMB7 in two MM cells. Similarly, altered expression of these proteins was tested after co-inhibition of PSMB5 and PSMB7 using a suboptimal dose of each specific siRNA. ${ }^{+}, 25 \mathrm{nM} ;{ }^{++}, 150 \mathrm{nM} ;{ }^{+++} ; 175 \mathrm{nM}$. C. Similarly, Hut 78 cell was tested. ${ }^{*}$ represents statistically significant $(p<0.05)$ by Dunnett's post-test compared to control. 
which proteasome activities to co-inhibit should be based on the status of proteasome activity in each MM cell line, which can be accomplished by studying biomarkers using specimens derived from each MM patient, such as tumor cells and serum/plasma from peripheral blood [25].
Recent studies of the direct mechanisms of Btz resistance were derived analyzed various tumor cell lines, including MM [10, 11], lymphoma [26], leukemia [9, 27], lung cancer [12], and hepatocellular carcinoma [14], with Btz. These studies suggested that Btz resistance is

A Mice inocculated with RPMI-8226

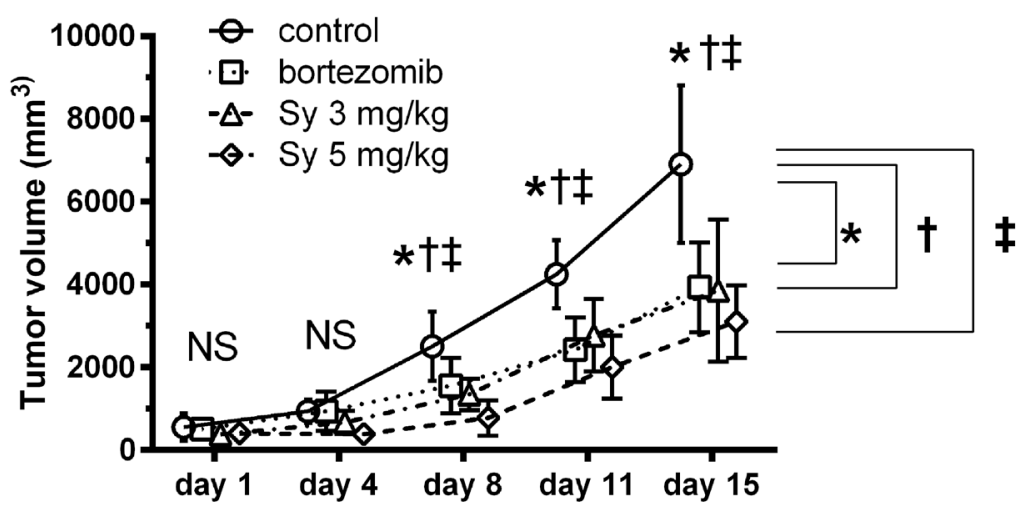

B

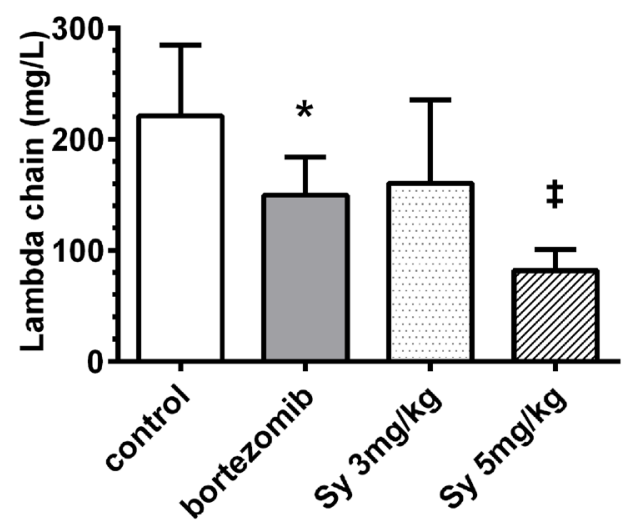

C

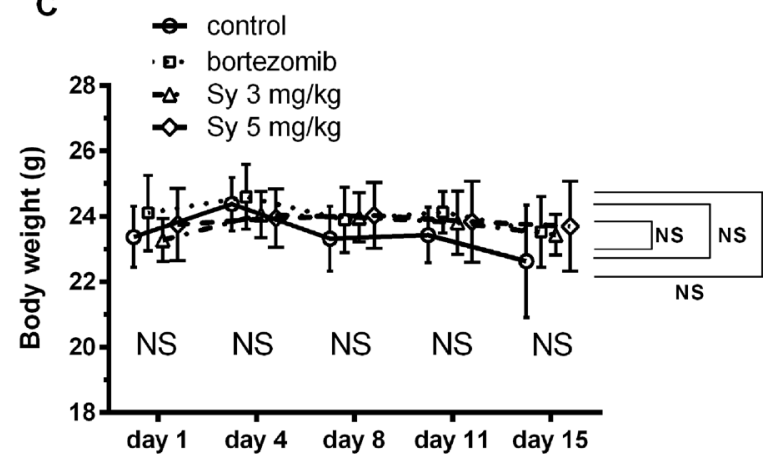

D

Mice inocculated with OPM-2/Btz

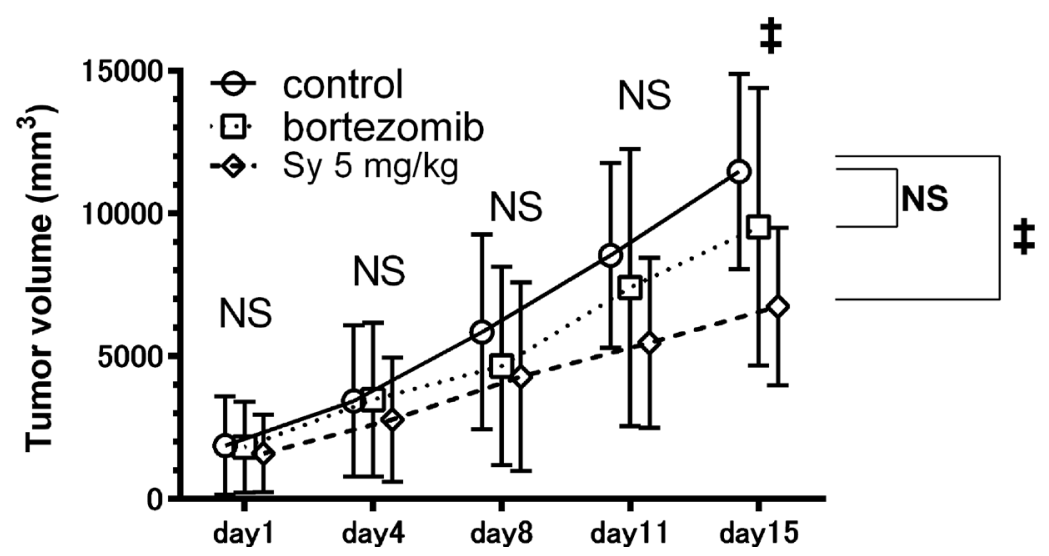

Figure 8: Syringolog-1 exerts anti-tumor activity in an in vivo MM model. (A) Average tumor volume in untreated mice (normal saline) and mice treated with either syringolog-1 (Sy) at 3 and $5 \mathrm{mg} / \mathrm{kg}$, or bortezomib (Btz) at $1 \mathrm{mg} / \mathrm{kg}$. (B) Average value of free light chains in plasma was measured in each treatment group on day 16. (C) Changes in body weight in each treatment group are shown. (D) Average tumor volume in mice inoculated with OPM-2//BTZ cells. Mice were divided into three groups, untreated, treated with either Sy at $5 \mathrm{mg} / \mathrm{kg}$, or Btz at $1 \mathrm{mg} / \mathrm{kg} .{ }^{*}, \dagger, *$ represents statistically significant $(p<0.05)$ by Dunnett's post-test, compared to control. 
Table 1: The $\mathrm{IC}_{50}$ of $\mathrm{MM}$, lymphoma, and bortezomib resistant cell lines in each drug

\begin{tabular}{|c|c|c|c|c|c|}
\hline \multirow[b]{3}{*}{ Cell type } & \multirow[b]{3}{*}{ Cell name } & \multicolumn{2}{|c|}{ Syringolog-1 } & \multicolumn{2}{|c|}{ Bortezomib } \\
\hline & & $\mathrm{IC}_{50}$ & $\mathrm{IC}_{50}$ & $\mathrm{IC}_{50}$ & $\mathbf{I C}_{50}$ \\
\hline & & $(\mathrm{nM})$ & ratio * & $(\mathrm{nM})$ & ratio * \\
\hline \multicolumn{6}{|l|}{$M M$} \\
\hline & U266 & 5.9 & & 15 & \\
\hline & RPMI8226 & 6.4 & & 20.1 & \\
\hline & KMS-11 & 5.7 & & 5.4 & \\
\hline & OPM-2 & 1.3 & & 2.8 & \\
\hline \multicolumn{6}{|c|}{ Lymphoma } \\
\hline & MT-4 & 1.2 & & 8.3 & \\
\hline & Hut-78 & 7.6 & & 22.5 & \\
\hline & Jurkat & 5.7 & & 37.4 & \\
\hline \multicolumn{6}{|c|}{ Btz resistant } \\
\hline & KMS-11/Btz & 17.4 & 3.1 & 240 & 44.4 \\
\hline & OPM-2/Btz & 5.1 & 3.9 & 293 & 104.6 \\
\hline & MT-4/Btz & 6.4 & 5.3 & 69.5 & 8.4 \\
\hline
\end{tabular}

${ }^{*}$ Comparison with parental cell line. $\quad$ Btz, bortezomib.

After the incubation with each drug for $72 \mathrm{hrs}$, the $\mathrm{IC}_{50}$ values were determined.

controlled by multiple factors, including alterations in PSMB5 expression or sequence, adjustment of biosynthesis of new proteins to reduce the ER stress [27], and upregulation of multiple proteasome subunits, such as $\beta 2$ and $\beta 5$ subunits, which enables cells to adapt to the selective proteasome inhibition resulting from Btz treatment. The therapeutic potential of targeting T-L activity in addition to inhibiting CT-L activity was proposed by a previous study [28]. In this study, the specific $\beta 2$ inhibitor LU-102 showed synergistic proteasome inhibition and activated the UPR and cytotoxicity in Btz-resistant MM cells when combined with Btz and Cfz treatment. Although the combination of LU-102 and Btz or Cfz is an attractive treatment strategy, monotherapy with LU-102 showed lower cytotoxicity in Btz-resistant MM cells, suggesting that selective elimination of T-L activity alone is insufficient to have a meaningful anti-tumor effect on Btz-resistant $\mathrm{MM}$ cells [28]. From this report, although co-inhibition of PSMB5 and $P S M B 7$ on Btz-resistant cells was not tested in our study, dual inhibition of CT-L and T-L activities, rather than single inhibition, is indispensable for triggering excessive ER stress and sequential fatal cell stress in Btz-resistant MM cells. In addition, LU-102 has been reported to have several limitations to its potential clinical use, including the need for a high concentration for anti-tumor activity and poor tolerability because of the high amount of vinyl sulfone in combination with Btz observed in a murine model [28]. In the current study, we identified a new syringolin analog, syringolog- 1 , and characterized its dual inhibition of CT-L and T-L activity by monotherapy. As previously reported, cells treated with Btz exhibit elevated expression of the $\beta 2$ and $\beta 5$ subunits $[11,14,27]$. In addition, inhibiting $P S M B 7$ was reported to re-sensitize MM cells during Btz treatment [29]. Therefore, this compound is expected to have an anti-tumor effect on Btz-resistant MM cells through the co-inhibition of CT-L and T-L activities and may be clinically useful against Btz-resistant MM cells as a single or combination therapy with other agents, such as Btz and Cfz.

Among the several factors associated with the cell survival and apoptosis, HSP70, a member of the cellprotective chaperon, was elevated during syringolog-1 treatment. This elevation was also observed in Btz treatment [30], which is considered a feedback action of the cells to reduce fatal intracellular stress during proteasome inhibition. Therefore, to maximize the antitumor effect of syringolog-1, a combination with a HSP70 inhibitor may be a therapeutic strategy to repress the compensatory action of cell to avoid lethal conditions [31].

In summary, our results demonstrate that the novel syringolin compound syringolog-1 dually inhibited CT-L and T-L proteasome activities, triggering high ER stress and related apoptosis in Btz-resistant MM cells. Our data suggest that targeting both CT-L and T-L activities can overcome Btz resistance, and therefore a dual inhibitor of the $\beta 2$ and $\beta 5$ subunits may be a new treatment option for patients with Btz/Cfz-resistant MM cells, who have poor treatment options for this incurable disease. 


\section{MATERIALS AND METHODS}

\section{Cell culture and reagents}

In this study, five human MM cell lines, KMS-11, OPM-2, NOP-1, U266, and RPMI8226; and 3 malignant lymphomas cells, MT-4, Jurkat, and Hut78; were used and cultured in RPMI-1640 medium supplemented with heat-inactivated $10 \%$ fetal bovine serum at $37^{\circ} \mathrm{C}$ in a $5 \%$ $\mathrm{CO}_{2}$ incubator $[25,32,33]$. Two Btz-resistant MM cells, KMS-11/Btz and OPM-2/Btz, were described previously [10]. Btz was purchased from Wako Pure Chemical Industries (Osaka, Japan). Syringolog-1 was synthesized as previously described [17].

\section{Isolation of primary MM specimens and peripheral blood mononuclear cell from healthy individual}

A total of 8 primary MM cell samples, derived from 3 patients with newly diagnosed (ND) MM and 5 patients with relapsed and or refractory (RR) MM, were tested in the cytotoxic and 20S proteasome assays. Of the 8 patients, 3 patients, including 2 RR and 1 ND cases, were clinically refractory to Btz-based therapy, while the other 5 patients were not refractory to Btz-based therapy. In this study, a patient was defined as clinically refractory to Btz based on the International Myeloma Working Group criteria and defined as follows: 1) RR cases nonresponsive or showing progressive disease with Btz-based therapy or within 60 days of the last Btz-based therapy [34], 2) ND cases showing non-responsive to the first Btzbased therapy [1]. In the immunoblot analysis, 3 primary MM samples with sufficient cell numbers for the analysis were selected. These samples include 1 sample from the above 8 samples, and other 2 samples form patients with ND MM additionally tested.

Bone marrow aspiration specimens from patients with MM were collected prior to the first (ND MM case) or second (RR MM case) treatment after written informed consent was obtained at Nagoya City University Hospital. Primary MM cells were isolated from the bone marrow mononuclear cell fraction using anti-CD138 antibodyconjugated magnetic beads with an AutoMACS Pro Separator, an automatic magnetic cell sorting system (Miltenyi Biotec, Bergisch Gladbach, Germany). To minimize the effect of contamination with normal plasma cells, only bone marrow specimens for which clonal proliferation of MM cells was confirmed by both pathological diagnosis and flow cytometric analysis were used in this study. In addition, to standardize the experimental conditions, all bone marrow specimens were immediately purified and assayed. PBMCs were obtained from four healthy individuals using Ficoll-Paque (Pharmacia, Uppsala, Sweden). This study protocol using human samples was approved by the Nagoya City
University Hospital Institutional Review Board.

\section{Cell proliferation, cytotoxicity, and apoptosis assays}

Cell proliferation and cytotoxicity assays were performed as described previously [33]. The $\mathrm{IC}_{50}$ value of each agent was calculated by GraphPad Prism version 6.05 for Windows (GraphPad Software, La Jolla, CA, USA). Apoptosis of cells exposed to syringolog-1 or Btz for 16 $\mathrm{h}$ was evaluated using annexin V-FITC and propidium iodide staining (Medical \& Biological Laboratories, Nagoya, Japan). The fraction of positive cells was determined using an FACS Calibur (BD Bioscience, San Jose, CA, USA). To evaluate apoptosis, only Annexin V-FITC-positive cells, indicating the progression of early apoptosis, were used to calculate the specific apoptosis. Specific apoptosis was calculated as $100 \times(\%$ induced apoptotic cells - \% spontaneous apoptotic cells) / (100 - \% spontaneous apoptotic cells).

All expressed values represent the mean value of triplicate experiments and the $\mathrm{IC}_{50}$ values were calculated using the mean value for each concentration of agent.

\section{$20 S$ proteasome activity assays}

A total of $5 \times 10^{5}$ cells were incubated with syringolog-1 or bortezomib for $6 \mathrm{~h}$. After washing twice with cold phosphate-buffered saline, the cells were resuspended in $50 \mathrm{mM}$ Tris (pH 7.4) buffer containing $5 \mathrm{mM} \mathrm{MgCl}_{2}$ and $0.2 \mathrm{mg} / \mathrm{mL}$ digitonin, which permeabilizes the cell membrane without disrupting it. Cells were transferred into 96-well flatbottom plates at a final concentration of $4 \times 10^{4}$ cells in 160 $\mu \mathrm{L}$ of buffer per well. Next, $40 \mu \mathrm{L}$ of fluorogenic substrate, Suc-LLVY-amc (Enzo Life Sciences, NY, USA) for CT-L, Boc-LRR-amc for T-L and Boc-LLE-amc for C-L activities was added to each well at a final concentration of $75 \mu \mathrm{M}$. After incubation for $3 \mathrm{~h}$ at $37^{\circ} \mathrm{C}$, fluorescence was measured at an excitation wavelength of $380 \mathrm{~nm}$ and emission wavelength of $460 \mathrm{~nm}$. All expressed values represent the average of triplicate experiments.

\section{Cell cycle analysis}

The cell cycle was analyzed with the BrdU Flow Kit (BD Biosciences). Cells were incubated with $10 \mathrm{nM}$ syringolog-1 for $16 \mathrm{~h}$, and then collected and assayed according to the manufacture instructions. Briefly, cells were fixed in $70 \%$ cold ethanol for $30 \mathrm{~min}$ on ice and incubated with FITC-conjugated anti-BrdU antibody in PBS containing $0.1 \%$ bovine serum albumin for 30 min. Cells were washed in PBS, stained with 7-AAD and analyzed on a FACS Calibur to assess cell cycle distribution. 


\section{Immunoblot analysis}

MM cell lines and primary MM samples were incubated with syringolog-1 or Btz for the indicated times. Preparation of whole-cell extracts and their analysis was carried out as described previously [26]. Antibodies against ubiquitin, CHOP, ERK1/2, p-ERK1/2, ATF3, XBP1, and actin were purchased from Santa Cruz Biotechnology (Dallas, TX, USA). Antibodies against cleaved caspase 3, HSP70, c-JUN, p-c-JUN, p27, and the $\beta 2$ proteasome subunit were purchased from Cell Signaling Technology (Danvers, MA, USA). The antibody against caspase 8 was purchased from BD Bioscience (Franklin Lakes, NJ, USA). The antibody against the $\beta 5$ proteasome subunit was purchased from Abcam (Cambridge, UK).

\section{RNA interference assays}

Small interfering RNA (siRNA) was used to repress the expression of PSMB5 and PSMB7 mRNA. PSMB5 siRNA (ID s11354), PSMB7 siRNA (ID s668), and Silencer Select Negative siRNA (ID 4390843) for the nontargeting control were purchased from Applied Biosystems (Foster City, CA, USA). Electroporation was carried out with the aid of a Nucleofector 2b device (Lonza, Basel, Switzerland) according to the manufacturer's instructions. Briefly, $2 \times 10^{6} \mathrm{U} 266$ cells in kit $\mathrm{C}$ nucleofector solution containing siRNA were electroporated using the X-005 program, transferred into culture plates, and incubated. Similarly, KMS-11 cells in kit L nucleofector solution with siRNA were electroporated using the X-001 program and Hut-78 cells in kit R nucleofector solution with siRNA were electroporated using the $\mathrm{V}-001$ program.

\section{Quantitative real-time reverse transcription PCR}

Total RNA was extracted from purified MM cells stored at $-80^{\circ} \mathrm{C}$ with RNeasy Mini kits (Qiagen, Hilden, Germany). Reverse transcription and amplification of total RNA was performed using the High capacity RNA-tocDNA kit (Thermo Fisher Scientific, Waltham, MA, USA). Quantitative PCR was carried out with SYBR Green Gene Expression Assays (Toyobo, Osaka, Japan) and a Step One Plus Real-Time PCR instrument (Applied Biosystems) according to the respective manufacturers' instructions. Targeted primer sets for real-time PCR (PSMB5, PSMB7, and actin) were purchased from Takara Bio (Shiga, Japan). The values of all samples were determined by calculating the means of duplicate samples, and adjusted to the expression of actin mRNA as an endogenous control.

\section{Murine xenograft model}

Six-week-old male CB-17/Icr-scid Jcl mice were purchased from CLEA Japan (Tokyo, Japan). All in vivo experiments were performed in conformity with the UK Coordinating Committee on Cancer Research Guidelines for the Welfare of Animals in Experimental Neoplasia (Second Edition). A quantity of $5 \times 10^{6}$ RPMI8226 cells suspended in $100 \mu \mathrm{L}$ RPMI-1640 medium with 50\% Corning Matrigel Basement Matrix (Corning, Inc., Corning, NY, USA) were inoculated subcutaneously into SCID mice. One day before tumor inoculation, $50 \mu \mathrm{L}$ of rabbit anti-asialo-GM1 (Wako Pure Chemical Industries, Osaka, Japan) was administered intraperitoneally. Ten days after tumor inoculation, the tumor-bearing mice were divided into four groups of six mice each so that the mean tumor volumes were approximately equal in the four groups. Tumor volume was calculated by the following formula: tumor volume $\left(\mathrm{mm}^{3}\right)=0.5 \times$ (major diameter $) \times($ minor diameter $) \times($ minor diameter $)$. Mice were treated by intraperitoneal injection of 3.0 or $5.0 \mathrm{mg} /$ $\mathrm{kg}$ syringolog-1 twice weekly, or intraperitoneal injection of $1.0 \mathrm{mg} / \mathrm{kg}$ Btz twice weekly. Control group mice were injected with saline. The level of free light chain in plasma was measured using a Free Light Chain Assay kit (Binding Site, Birmingham, UK). Similarly, six-week-old male NOD/ShiJic-scidJcl mice inoculated with OPM-2/Btz, a Btz resistant cell, were tested.

\section{Statistical analysis}

Analyses were carried out using GraphPad Prism software. Data comparison in multiple groups was carried out by one-way analysis of variance, and the further comparisons between two groups were followed by Dunnett's post-test. Two-tailed Student's $t$-test was performed to compare two groups according to the distribution of data. $P$ value of $<0.05$ was considered statistically significant.

\section{Author contributions}

TY and MR performed the research and wrote the paper. TK, SA, RA, SK (Sho Aoki), TN, HT, and SK assisted in performing experiments. AM, AI, SK (Shigeru Kusumoto), TI, and HK conducted, data analysis and interpretation. SK, TC, and SI contributed to synthesis of syringolog-1. MR and SI designed the research study. SI (Satoshi Ichikawa) and SI (Shinsuke Iida) supervised the study.

\section{ACKNOWLEDGMENTS}

We thank Ms. Chiori Fukuyama for her skillful technical assistance. We would like to thank Editage (www.editage.jp) for English language editing.

\section{CONFLICTS OF INTEREST}

MR received research funding from Celgene Co., 
Ltd. TI received research funding from Kyowa Hakko Kirin Co., Ltd., Bayer Pharma AG, and J-Pharma Co., Ltd. TI also received Honoraria from Kyowa Hakko Kirin Co., Ltd. SI received research funding and declares Honoraria from Janssen Pharmaceutical K.K., and Celgene Co., Ltd. SI also received research funding from Kyowa Hakko Kirin Co., Ltd., Chugai Pharmaceutical Co., Ltd, Bristol-Myers Squibb, Ono Pharmaceutical CO., Ltd, Nippon Kayaku CO., Ltd. Eli Lilly Japan K.K., and Bayer Yakuhin, Ltd.

\section{FUNDING}

This work was partly supported by a Grant-in-Aids for Scientific Research from the Ministry of Education, Culture, Sports, Science and Technology (16K07179 \& 16K09855), National Cancer Center Research and Development Fund (28-A-4), and Practical Research for Innovative Cancer Control from Japan Agency for Medical Research and development, AMED. This study was partly supported by the JSPS Grant-in-Aid for Challenging Exploratory Research (SI, Grant Number 22659020), Scientific Research (B) (SI, Grant Number 25293026), Scientific Research on Innovative Areas "Chemical Biology of Natural Products" (SI, Grant Number 24102502), Hokkaido University, Global Facility Center (GFC), Pharma Science Open Unit (PSOU), funded by MEXT under "Support Program for Implementation of New Equipment Sharing System", Platform Project for Supporting in Drug Discovery and Life Science Research (Platform for Drug Discovery, Informatics, and Structural Life Science) from the Ministry of Education, Culture, Sports, Science and Technology (MEXT), and Japan Agency for Medical Research and Development (AMED).

\section{REFERENCES}

1. Rajkumar SV, Dimopoulos MA, Palumbo A, Blade J, Merlini G, Mateos MV, Kumar S, Hillengass J, Kastritis E, Richardson P, Landgren O, Paiva B, Dispenzieri A, et al. International Myeloma Working Group updated criteria for the diagnosis of multiple myeloma. Lancet Oncol. 2014; 15: e538-48. https://doi.org/10.1016/S1470-2045(14)70442-5.

2. San Miguel JF, Schlag R, Khuageva NK, Dimopoulos MA, Shpilberg O, Kropff M, Spicka I, Petrucci MT, Palumbo A, Samoilova OS, Dmoszynska A, Abdulkadyrov KM, Schots $\mathrm{R}$, et al, and VISTA Trial Investigators. Bortezomib plus melphalan and prednisone for initial treatment of multiple myeloma. N Engl J Med. 2008; 359:906-17. https://doi. org/10.1056/NEJMoa0801479.

3. Moreau P, Masszi T, Grzasko N, Bahlis NJ, Hansson M, Pour L, Sandhu I, Ganly P, Baker BW, Jackson SR, Stoppa AM, Simpson DR, Gimsing P, et al, and TOURMALINEMM1 Study Group. Oral Ixazomib, Lenalidomide, and Dexamethasone for Multiple Myeloma. N Engl J Med. 2016; 374:1621-34. https://doi.org/10.1056/NEJMoa1516282.
4. Stewart AK, Rajkumar SV, Dimopoulos MA, Masszi T, Špička I, Oriol A, Hájek R, Rosiñol L, Siegel DS, Mihaylov GG, Goranova-Marinova V, Rajnics P, Suvorov A, et al, and ASPIRE Investigators. Carfilzomib, lenalidomide, and dexamethasone for relapsed multiple myeloma. N Engl J Med. 2015; 372:142-52. https://doi.org/10.1056/NEJMoa1411321.

5. Obeng EA, Carlson LM, Gutman DM, Harrington WJ Jr, Lee KP, Boise LH. Proteasome inhibitors induce a terminal unfolded protein response in multiple myeloma cells. Blood. 2006; 107:4907-16. https://doi.org/10.1182/blood-2005-08-3531.

6. Manasanch EE, Korde N, Zingone A, Tageja N, Fernandez de Larrea C, Bhutani M, Wu P, Roschewski M, Landgren O. The proteasome: mechanisms of biology and markers of activity and response to treatment in multiple myeloma. Leuk Lymphoma. 2014; 55:1707-14. https://doi.org/10.31 09/10428194.2013.828351.

7. Potts BC, Albitar MX, Anderson KC, Baritaki S, Berkers C, Bonavida B, Chandra J, Chauhan D, Cusack JC Jr, Fenical W, Ghobrial IM, Groll M, Jensen PR, et al. Marizomib, a proteasome inhibitor for all seasons: preclinical profile and a framework for clinical trials. Curr Cancer Drug Targets. 2011; 11:254-84.

8. Muz B, Ghazarian RN, Ou M, Luderer MJ, Kusdono HD, Azab AK. Spotlight on ixazomib: potential in the treatment of multiple myeloma. Drug Des Devel Ther. 2016; 10:21726. https://doi.org/10.2147/DDDT.S93602.

9. Oerlemans R, Franke NE, Assaraf YG, Cloos J, van Zantwijk I, Berkers CR, Scheffer GL, Debipersad K, Vojtekova K, Lemos C, van der Heijden JW, Ylstra B, Peters GJ, et al. Molecular basis of bortezomib resistance: proteasome subunit beta5 (PSMB5) gene mutation and overexpression of PSMB5 protein. Blood. 2008; 112:248999. https://doi.org/10.1182/blood-2007-08-104950.

10. Ri M, Iida S, Nakashima T, Miyazaki H, Mori F, Ito A, Inagaki A, Kusumoto S, Ishida T, Komatsu H, Shiotsu Y, Ueda R. Bortezomib-resistant myeloma cell lines: a role for mutated PSMB5 in preventing the accumulation of unfolded proteins and fatal ER stress. Leukemia. 2010; 24:1506-12. https://doi.org/10.1038/leu.2010.137.

11. Balsas P, Galan-Malo P, Marzo I, Naval J. Bortezomib resistance in a myeloma cell line is associated to PSMbeta5 overexpression and polyploidy. Leuk Res. 2012; 36:212-8. https://doi.org/10.1016/j.leukres.2011.09.011.

12. de Wilt LH, Jansen G, Assaraf YG, van Meerloo J, Cloos J, Schimmer AD, Chan ET, Kirk CJ, Peters GJ, Kruyt FA. Proteasome-based mechanisms of intrinsic and acquired bortezomib resistance in non-small cell lung cancer. Biochem Pharmacol. 2012; 83:207-17. https://doi. org/10.1016/j.bcp.2011.10.009.

13. Mitsiades N, Mitsiades CS, Poulaki V, Chauhan D, Fanourakis G, Gu X, Bailey C, Joseph M, Libermann TA, Treon SP, Munshi NC, Richardson PG, Hideshima T, et al. Molecular sequelae of proteasome inhibition in human multiple myeloma cells. Proc Natl Acad Sci U S A. 2002; 99:14374-9. https://doi.org/10.1073/pnas.202445099. 
14. Wu YX, Yang JH, Saitsu H. Bortezomib-resistance is associated with increased levels of proteasome subunits and apoptosis-avoidance. Oncotarget. 2016; 7:77622-34. https://doi.org/10.18632/oncotarget.12731.

15. Groll M, Schellenberg B, Bachmann AS, Archer CR, Huber R, Powell TK, Lindow S, Kaiser M, Dudler R. A plant pathogen virulence factor inhibits the eukaryotic proteasome by a novel mechanism. Nature. 2008; 452:7558. https://doi.org/10.1038/nature06782.

16. Bachmann AS, Opoku-Ansah J, Ibarra-Rivera TR, Yco LP, Ambadi S, Roberts CC, Chang CE, Pirrung MC. Syrbactin Structural Analog TIR-199 Blocks Proteasome Activity and Induces Tumor Cell Death. J Biol Chem. 2016; 291:8350 62. https://doi.org/10.1074/jbc.M115.710053.

17. Chiba T, Hosono H, Nakagawa K, Asaka M, Takeda H, Matsuda A, Ichikawa S. Total synthesis of syringolin A and improvement of its biological activity. Angew Chem Int Ed Engl. 2014; 53:4836-9. https://doi.org/10.1002/ anie. 201402428.

18. Kitahata S, Chiba T, Yoshida T, Ri M, Iida S, Matsuda A, Ichikawa S. Design, Synthesis, and Biological Activity of Isosyringolin A. Org Lett. 2016; 18:2312-5. https://doi. org/10.1021/acs.orglett.6b01053.

19. Britton M, Lucas MM, Downey SL, Screen M, Pletnev AA, Verdoes M, Tokhunts RA, Amir O, Goddard AL, Pelphrey PM, Wright DL, Overkleeft HS, Kisselev AF. Selective inhibitor of proteasome's caspase-like sites sensitizes cells to specific inhibition of chymotrypsin-like sites. Chem Biol. 2009; 16:1278-89. https://doi.org/10.1016/j. chembiol.2009.11.015.

20. Kisselev AF, Callard A, Goldberg AL. Importance of the different proteolytic sites of the proteasome and the efficacy of inhibitors varies with the protein substrate. J Biol Chem. 2006; 281:8582-90. https://doi.org/10.1074/ jbc.M509043200.

21. Hajek R, Masszi T, Petrucci MT, Palumbo A, Rosinol L, Nagler A, Yong KL, Oriol A, Minarik J, Pour L, Dimopoulos MA, Maisnar V, Rossi D, et al. A randomized phase III study of carfilzomib vs low-dose corticosteroids with optional cyclophosphamide in relapsed and refractory multiple myeloma (FOCUS). Leukemia. 2017; 31:107-14. https://doi.org/10.1038/leu.2016.176.

22. Mitsiades N, Mitsiades CS, Poulaki V, Chauhan D, Richardson PG, Hideshima T, Munshi NC, Treon SP, Anderson KC. Apoptotic signaling induced by immunomodulatory thalidomide analogs in human multiple myeloma cells: therapeutic implications. Blood. 2002; 99:4525-30

23. Dimopoulos MA, Moreau P, Palumbo A, Joshua D, Pour L, Hájek R, Facon T, Ludwig H, Oriol A, Goldschmidt H, Rosiñol L, Straub J, Suvorov A, et al, and ENDEAVOR Investigators. Carfilzomib and dexamethasone versus bortezomib and dexamethasone for patients with relapsed or refractory multiple myeloma (ENDEAVOR): a randomised, phase 3, open-label, multicentre study. Lancet Oncol. 2016; 17:27-38. https:// doi.org/10.1016/S1470-2045(15)00464-7.
24. Badros AZ, Papadopoulos KP, Zojwalla N, Lee JR, Siegel DS. A Phase $1 \mathrm{~b}$ Study of 30-Minute Infusion Carfilzomib 20/45 and 20/56 Mg/m2 Plus $40 \mathrm{Mg}$ Weekly Dexamethasone in Patients with Relapsed and/or Refractory (R/R) Multiple Myeloma. Blood. 2012; 120: 4036.

25. Narita T, Ri M, Masaki A, Mori F, Ito A, Kusumoto S, Ishida T, Komatsu H, Iida S. Lower expression of activating transcription factors 3 and 4 correlates with shorter progression-free survival in multiple myeloma patients receiving bortezomib plus dexamethasone therapy. Blood Cancer J. 2015; 5: e373. https://doi.org/10.1038/ bcj.2015.98.

26. Pérez-Galán P, Mora-Jensen H, Weniger MA, Shaffer AL 3rd, Rizzatti EG, Chapman CM, Mo CC, Stennett LS, Rader C, Liu P, Raghavachari N, Stetler-Stevenson $\mathrm{M}$, Yuan C, et al. Bortezomib resistance in mantle cell lymphoma is associated with plasmacytic differentiation. Blood. 2011; 117:542-52. https://doi.org/10.1182/ blood-2010-02-269514.

27. Ruckrich T, Kraus M, Gogel J, Beck A, Ovaa H, Verdoes M, Overkleeft HS, Kalbacher H, Driessen C. Characterization of the ubiquitin-proteasome system in bortezomibadapted cells. Leukemia. 2009; 23:1098-105. https://doi. org/10.1038/leu.2009.8.

28. Kraus M, Bader J, Geurink PP, Weyburne ES, Mirabella AC, Silzle T, Shabaneh TB, van der Linden WA, de Bruin G, Haile SR, van Rooden E, Appenzeller C, Li N, et al. The novel beta2-selective proteasome inhibitor LU-102 synergizes with bortezomib and carfilzomib to overcome proteasome inhibitor resistance of myeloma cells. Haematologica. 2015; 100:1350-60. https://doi.org/10.3324/haematol.2014.109421.

29. Zhu YX, Tiedemann R, Shi CX, Yin H, Schmidt JE, Bruins LA, Keats JJ, Braggio E, Sereduk C, Mousses S, Stewart AK. RNAi screen of the druggable genome identifies modulators of proteasome inhibitor sensitivity in myeloma including CDK5. Blood. 2011; 117:3847-57. https://doi. org/10.1182/blood-2010-08-304022.

30. Shringarpure R, Catley L, Bhole D, Burger R, Podar K, Tai YT, Kessler B, Galardy P, Ploegh H, Tassone P, Hideshima T, Mitsiades C, Munshi NC, et al. Gene expression analysis of B-lymphoma cells resistant and sensitive to bortezomib. Br J Haematol. 2006; 134:145-56. https://doi.org/10.1111/ j.1365-2141.2006.06132.x.

31. Teoh PJ, Bi C, Sintosebastian C, Tay LS, Fonseca R, Chng WJ. PRIMA-1 targets the vulnerability of multiple myeloma of deregulated protein homeostasis through the perturbation of ER stress via p73 demethylation. Oncotarget. 2016; 7:61806-19. https://doi.org/10.18632/oncotarget.11241.

32. Ri M, Iida S, Ishida $\mathrm{T}$, Ito $\mathrm{A}$, Yano H, Inagaki A, Ding J, Kusumoto S, Komatsu H, Utsunomiya A, Ueda R. Bortezomib-induced apoptosis in mature T-cell lymphoma cells partially depends on upregulation of Noxa and functional repression of Mcl-1. Cancer Sci. 2009; 100:3418. https://doi.org/10.1111/j.1349-7006.2008.01038.x.

33. Ri M, Tashiro E, Oikawa D, Shinjo S, Tokuda M, Yokouchi Y, Narita T, Masaki A, Ito A, Ding J, Kusumoto S, Ishida T, 
Komatsu H, et al. Identification of Toyocamycin, an agent cytotoxic for multiple myeloma cells, as a potent inhibitor of ER stress-induced XBP1 mRNA splicing. Blood Cancer J. 2012; 2: e79. https://doi.org/10.1038/bcj.2012.26.

34. Kumar S, Paiva B, Anderson KC, Durie B, Landgren O, Moreau P, Munshi N, Lonial S, Blade J, Mateos
MV, Dimopoulos M, Kastritis E, Boccadoro M, et al. International Myeloma Working Group consensus criteria for response and minimal residual disease assessment in multiple myeloma. Lancet Oncol. 2016; 17: e328-e46. https://doi.org/10.1016/s1470-2045(16)30206-6. 